\title{
Examining adherence and sexual behavior among patients on antiretroviral therapy in India
}

\author{
Avina Sarna \\ Population Council \\ Indrani Gupta \\ Sanjay Pujari \\ A.K. Sengar \\ Rajiv Garg
}

See next page for additional authors

Follow this and additional works at: https://knowledgecommons.popcouncil.org/departments_sbsr-hiv

Part of the Demography, Population, and Ecology Commons, Health Economics Commons, Health Policy Commons, Immune System Diseases Commons, International Public Health Commons, Medicine and Health Commons, Public Health Education and Promotion Commons, and the Virus Diseases Commons How does access to this work benefit you? Let us know!

\section{Recommended Citation}

Sarna, Avina, Indrani Gupta, Sanjay Pujari, A.K. Sengar, Rajiv Garg, and Ellen Weiss. 2006. "Examining adherence and sexual behavior among patients on antiretroviral therapy in India," Horizons Final Report. Washington, DC: Population Council. 


\section{Authors}

Avina Sarna, Indrani Gupta, Sanjay Pujari, A.K. Sengar, Rajiv Garg, and Ellen Weiss 


\section{Horizons}

Examining Adherence and Sexual Behavior Among Patients on Antiretroviral Therapy in India
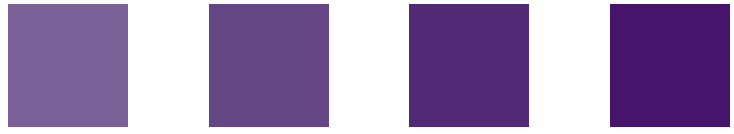

Horizons Program

Institute of Economic Growth

Ruby Hall Clinic

Northern Railway Hospital

Employees State Insurance Corporation 


\title{
Examining Adherence and Sexual Behavior Among Patients on Antiretroviral Therapy in I ndia
}

\author{
Avina Sarna, Horizons/Population Council, \\ Indrani Gupta, Institute of Economic Growth, \\ Sanjay Pujari, Ruby Hall Clinic, \\ A. K. Sengar, Northern Railway Hospital, \\ Rajiv Garg, Employees State Insurance Corporation, and \\ Ellen Weiss, Horizons/International Center for Research on Women
}




\section{Acknowledgments}

The authors would like to thank the study participants for their time and insight.

We would like to thank the administration of Northern Railway Hospital, Employees State Insurance Corporation, and Ruby Hall Clinic for their support in conducting this study. A special thanks to Dr. A. K. Khokhar, former deputy medical commissioner and project director of the Employees State Insurance Corporation/National AIDS Control Organization Project, and Dr. Amita Rawal, chief medical superintendent of Northern Railway Hospital for supporting this research.

We would like to thank Dr. R. R. Gangakhedkar from NARI Pune; Dr. Saroj Pachauri, regional director of the Population Council's South East Asia region; Lindsay Flury, consultant with the Horizons Program; Dr. Johannes van Dam, director of the Reproductive Health Program at the Population Council; and Dr. Naomi Rutenberg, director of the Horizons Program at the Population Council for their insightful comments and careful review of the manuscript.

We would like to acknowledge Mr. Rajendra Prasad for his support with data management, Dr. Anurag Misra from the FRONTIERS Program of the Population Council for his expertise with data analysis and Mr. V. L. Thomas of the Horizons Program for administrative support.

This study could not have been done without the members of our research team: Dr. Sanjay Katke, Dr. Nilofer Shaikh, Sheetal Sorabia, Milli Barua, Sandeep Rasapulkar, Pauline Gomes, and Mrudul Patil; our thanks to them.

We would like to thank members of the Technical Advisory Committee: Dr. R. R. Gangakhedkar from NARI Pune, Dr. Dora Warren from CDC India, Mr. K. K. Abraham of INP Plus, Dr. P. L. Joshi, former joint director NACO, and Dr. E. Naik of the University of South Florida.

Finally, thanks to Dr. Andy Fisher, former director of the Horizons Program/Population Council for his encouragement and support in conducting this study.

For further details, please contact Dr. Avina Sarna at asarna@popcouncil.org.

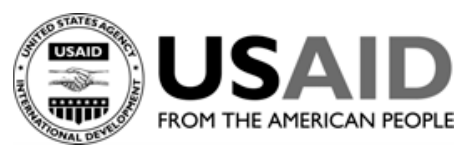

This project was funded by the Horizons Program. Horizons is implemented by the Population Council in collaboration with the International Center for Research on Women, International HIV/AIDS Alliance, PATH, Tulane University, Family Health International, and Johns Hopkins University. Horizons is funded by the President's Emergency Plan for AIDS Relief through the U.S. Agency for International Development, under the terms of HRN-A-000-97-00012-00. The opinions expressed herein are those of the authors and do not necessarily reflect the views of the U.S. Agency for International Development.

Published in April 2006

\section{(P) Population Council}

The Population Council is an international, non-profit, nongovernmental institution that seeks to improve the well-being and reproductive health of current and future generations around the world and to help achieve a humane, equitable, and sustainable balance between people and resources. The Council conducts biomedical, social science, and public health research and helps build research capacities in developing countries. Established in 1952, the Council is governed by an international board of trustees. Its New York headquarters supports a global network of country offices.

Copyright 2006 The Population Council Inc.

Suggested citation: Sarna, Avina, Indrani Gupta, Sanjay Pujari, A. K. Sengar, Rajiv Garg, and Ellen Weiss. 2006. "Examining adherence and sexual behavior among patients on antiretroviral therapy in India," Horizons Final Report. Washington, DC: Population Council.

This document may be reproduced in whole or in part without permission of the Population Council provided full source citation is given and the reproduction is not for commercial purposes. 


\section{Table of Contents}

\section{Acronyms and Abbreviations}

Executive Summary

I ntroduction

Methods

Objectives

Study design

Study sites

Study population and recruitment

Measures

Data analysis

Limitations of the study

Results

Characteristics of the sample

Adherence

Economic aspects of treatment

24

Sexual behavior 


\section{Acronyms and Abbreviations}

$\begin{array}{ll}\text { AACTG } & \text { Adult AIDS Clinical Trials Group } \\ \text { AIDS } & \text { Acquired immune deficiency syndrome } \\ \text { ARV } & \text { Antiretroviral } \\ \text { ART } & \text { Antiretroviral therapy } \\ \text { BDI } & \text { Beck Depression Inventory } \\ \text { CGHS } & \text { Central Government Health Scheme } \\ \text { ES } & \text { Economic status } \\ \text { ESIC } & \text { Employees State Insurance Corporation } \\ \text { HAART } & \text { Highly active antiretroviral therapy } \\ \text { MEMS } & \text { Medication Events Monitoring System } \\ \text { MSM } & \text { Men who have sex with men } \\ \text { NGO } & \text { Nongovernmental organization } \\ \text { NRTI } & \text { Non-nucleoside reverse transcriptase inhibitor } \\ \text { NRH } & \text { Northern Railway Hospital } \\ \text { RHC } & \text { Ruby Hall Clinic } \\ \text { TB } & \text { Tuberculosis }\end{array}$




\section{Executive Summary}

Very high levels of patient adherence (greater than 95 percent) are required for antiretroviral therapy (ART) to be effective and to prevent the emergence of resistant viral strains (Paterson et al. 2000; Ickovics et al. 2002). Since 1997, antiretroviral (ARV) medications have been available in India through the private sector and some employer-supported health insurance programs. It is estimated that India has 5.1 million HIV-infected persons (NACO 2004), some of whom have been on ART for several years. However, very little information is available on the levels of adherence to ART among people living with HIV/AIDS in India.

With increased availability of ART, HIV-positive individuals are living healthier lives and continuing or resuming sexual activity. But, optimism related to ART's success in slowing disease progression, reducing viral load, and improving health status may lead to more risky sexual practices and a possible increase in transmission of infections. Determining the sexual behavior of HIV-positive persons on ART is therefore an area of special interest and concern.

To meet these knowledge gaps, the Horizons Program, in collaboration with research partners in Delhi and Pune, conducted a study to assess current levels of adherence to ART among a sample of people living with HIV/AIDS, identify the factors that influence their adherence to treatment, and determine their sexual risk behaviors. The study also examined the economic burden of ART on the household. Findings from the study provide important insights that are immediately relevant to the scale-up of the national ART program, which was launched in April 2004.

\section{Methods}

Three hundred and ten HIV-positive patients currently on ART and attending one private and three public sector health facilities in Pune and Delhi were interviewed between May and August 2004. The sample of clients from the private clinic was mostly paying out-of-pocket for their treatment $(n=252 / 263)$. The remaining private clinic clients $(n=11)$ and those using the public sector facilities $(n=47)$ were receiving free ARVs through employer-provided, government-supported health insurance programs. A semi-structured questionnaire adapted from adherence instruments developed by the Adult AIDS Clinical Trials Group (AACTG) was used for data collection.

Adherence was measured using a 4-day patient self-report. Mean 4-day adherence was calculated by dividing the number of pills actually taken by the number of pills prescribed for 4 days $\mathrm{x} 100$.

Higher adherence was defined as a mean 4-day adherence of $\geq 90$ percent and lower adherence as a mean 4-day adherence of $<90$ percent. Other measures of adherence included (a) the number of missed doses over the last week, (b) the last time a full day of medication was missed, (c) the number of times treatment was stopped for more than one week, and (d) the frequency of following the medication dosage schedule.

The key themes of analysis for sexual risk behavior were type of partners, knowledge of partner's status, disclosure of one's own HIV status to partners, condom use at last sex, and consistent condom use. 


\section{Hgrizons}

\section{Characteristics of the Sample}

The mean age of respondents was 37 years (range 23-70 years). The majority of patients were employed (82 percent) and currently married ( 85 percent). Most were male ( 84 percent), although the percentage of women was higher in the group receiving free ARVs than in the group paying for the medication out-ofpocket ( 28 percent versus 13 percent). One reason for this difference is that employer-provided, government-supported insurance programs extend coverage to the families of employees.

Ninety-eight percent of respondents were on a non-protease-inhibitor-based treatment regimen. Eightyeight percent of respondents $(n=272)$ were on a first-line Nevirapine-based regimen; seven percent on an Efavirenz-based regimen $(n=22)$, and three percent $(n=9)$ on other combinations that include didanosine (DDI) and abacavir (ABC). Two percent $(n=7)$ were taking protease-inhibitor-based treatment regimens containing NRTI (nucleoside reverse transcriptase inhibitor) combinations with Ritonavir-boosted Indinavir or Nelfinavir.

\section{Key Findings}

\section{The mean 4-day adherence was high in this population; however, adherence decreased over} longer recall periods.

The self-reported mean 4-day adherence for the sample was 94.5 percent. Sixteen percent of respondents reported missing one or more doses over the last four days; more than a quarter of the respondents reported not having followed the medication schedule over the past four days. Twenty percent of respondents reported missed doses over the past seven days; a similar percentage reported missing a full day's medication within the last three months. Sixteen percent of respondents reported having stopped medications for more than a week at least once since initiating ART. There were no differences between males and females on these measures.

Commonly cited reasons for missing doses over the past week included being busy with other things and forgetting (38 percent), being away from home (34 percent), and running out of pills ( 26 percent). Half of those who ran out of pills reported stock-outs in public sector dispensaries. Not having money to purchase medications ( 5 percent), not understanding instructions ( 4 percent), and feeling ill ( 4 percent) were mentioned less frequently.

\section{Severe depression and obtaining free ARVs through insurance programs were the main predictors of lower adherence.}

Through multivariate analysis, severe depression and obtaining free ARVs were found to be significantly associated with lower adherence (defined as a mean 4-day adherence rate of $<90$ percent). Patients with severe depression were four times more likely to report lower adherence compared to those with minimal depression (95 percent CI 1.639-12.269, $\mathrm{p}=.002$ ) and patients receiving free ARVs were four times more likely to report lower adherence compared to patients paying out-of-pocket for their treatment (95 percent CI 1.422-11.542, $\mathrm{p}=.009)$. 


\section{Lower adherence was documented among patients receiving free ARVs, even after controlling for economic status.}

Mean 4-day adherence was significantly lower among patients receiving free ARVs through insurance programs compared to patients paying out-of-pocket $(81$ percent versus 96 percent, $p<0.001$ ).

Adherence in the group receiving free ARVs was lower for all other measures of adherence: missed doses over four days, missed doses over the last week, last time a full day of medication was missed, number of times treatment was stopped for more than one week, and frequency of following medication dosage schedule.

Adherence was lower among patients receiving free ARVs through insurance programs compared to patients paying out-of-pocket across the first three economic quartiles, even after controlling for economic status.

\section{For clients with no insurance coverage, being on ART is a heavy economic burden and most would switch to a free program, if available.}

The study found that for clients without any insurance coverage, being on ART is a heavy economic burden, which highlights the need for financing mechanisms that include paying for drugs and tests. At the same time, the results also suggest that zero out-of-pocket expenditure on treatment may be a deterrent to adherence, which means that more consideration should be given to the pricing of the treatment program in order to maximize adherence.

Seventy-one percent of clients who did not have any coverage and were paying out-of-pocket for their treatment said they would move to the free ARV program funded by the government if they could, mostly for financial reasons. Concerns about confidentiality and the quality of care and of medications in public sector facilities were the main reasons why 19 percent indicated that they would not switch to a government facility.

\section{Most respondents reported being sexually active in the past six months, primarily with a regular partner.}

Sixty-one percent of respondents reported having had sexual intercourse in the past six months. More respondents with minimal to mild depression, who started treatment at higher CD4 counts $\left(>200\right.$ cells $\left./ \mathrm{mm}^{3}\right)$, and who were married reported sexual activity in the past six months. No difference between men and women was noted in reported sexual activity. Time since diagnosis of HIV infection and time on ART were not associated with reporting sex.

The majority of respondents reported sex with a regular partner (96 percent); proportions were similar for men and women. All respondents who reported sex with a casual partner (4 percent) or a sex worker (2 percent) were men. No men reported sex with a male partner during the reference period. 


\section{Hgrizons}

\section{More respondents reported knowing the HIV status of their regular partner than reported disclosing their own status to them.}

Eighty-three percent of respondents who had sex with a regular partner reported knowing their partner's HIV status. More women reported having an HIV-positive regular partner while more men reported having an HIV-negative partner or one of unknown status. A smaller proportion (74 percent) of respondents reported having disclosed their HIV status to their regular partner. Proportions were similar for men and women.

None of the respondents who reported sex with a casual partner or sex worker knew that partner's HIV status or disclosed their own serostatus to them.

\section{Respondents with an HIV-positive partner and with minimal to mild depression were more likely to disclose their HIV status to a regular partner.}

The highest level of disclosure to a regular partner was observed among respondents with an HIVpositive partner (83 percent); lower disclosure rates were found among respondents with an HIV-negative partner (74 percent) and among those with a partner of unknown HIV status (52 percent; $p<0.003$ ). A significantly greater proportion of respondents with minimal to mild depression ( 94 percent) disclosed their HIV status to their regular partner than respondents with moderate to severe depression (78 percent; $\mathrm{p}=0.002)$.

\section{Reported condom use was high with regular partners.}

Eighty-nine percent of respondents who reported sex with a regular partner reported using a condom at last sex. There was no significant difference between men and women. All respondents who reported sex with a casual partner or sex worker reported using a condom at last sex with that type of partner.

Condom use at last sexual contact with a regular partner was associated with education, partner's HIV status, and depression. Respondents with less than five years of education (65 percent) reported significantly lower condom use when compared to those with 6-12 years of education ( 92 percent) and those with a university level of education (93 percent; $p=0.001$ ). Respondents with moderate to severe depression (78 percent) were less likely to report condom use at last sexual contact than respondents with minimal to mild depression (94 percent; $\mathrm{p}=0.002$ ). Respondents with an HIV-negative partner (96 percent) were more likely to report condom use at last sexual contact with a regular partner than respondents with a HIV-positive partner ( 83 percent) and with a partner of unknown status ( 87 percent; $p$ $=0.002$ ). Consistent condom use (always used a condom) with a regular partner was reported by 80 percent of respondents. 


\section{Program I mplications}

This exploratory study was conducted among HIV-infected individuals accessing ARVs in two categories of health service facilities: the private sector and the insurance-based public sector. Although the selfreported mean 4-day adherence was high among study participants, the data indicate that adherence was lower among patients who received free ART through insurance-based programs. No information is yet available on adherence levels among patients who are receiving free ARVs through the national ART program to which the data from this study can be compared. Therefore, there is a need for a larger multisite study that compares HIV-infected persons receiving free ART through the national ART program to HIV-positive clients of a range of private providers and private facilities to better understand the links between treatment adherence, financing of ART, and quality of care.

Findings of lower adherence among patients receiving free ARVs through insurance-based public sector facilities may be an early indicator of adherence levels among clients of the national ART program. These findings underscore the need for a strong monitoring and evaluation component in the national program as it scales up and a strong focus on (a) adequate preparation of patients prior to initiating ART, (b) regular assessment of adherence levels during follow-up, and (c) provision of ongoing adherence support for patients.

The national ART program needs to prepare for an influx of patients currently accessing care services in the private sector. Most respondents paying out-of-pocket for ART in this study would switch to a free program if they could. However, they have a number of concerns about the quality of care at government facilities (e.g., quality of ARV medications, confidentiality, continuous supply of medications) that should be considered by program administrators as the national ART program is rolled out.

The study found that while out-of-pocket expenses for treatment pose a significant economic burden on clients who pay for services, these expenses could also influence adherence positively. Policymakers may want to consider a pilot project to assess optimal levels of user fees to maximize adherence yet minimize the economic burden of ART on households..

Given that severe depression was a key predictor of lower adherence, health providers should check for this condition during adherence risk assessment of patients before ART is initiated. Consideration during adherence counseling should also be given to other factors that were found to influence adherence in this study, such as lower education levels, starting ART at higher CD4 cell counts, being unemployed, having moderate to severe side effects as a result of taking ART, and taking four or more medications.

The evidence from this study highlights the need to expand the scope of prevention programs to include HIV-positive populations, with a special focus on facilitating disclosure of HIV status and consistent condom use with regular partners. Interventions that integrate HIV prevention activities with HIV/AIDS care services are required.

This study included relatively few women. Although the respondents were not representative of the entire population accessing ART services in India, the low figure still calls attention to the need for policymakers to make sure that women are included in the national ART program. 


\section{Hgrizons}

\section{I ntroduction}

Antiretroviral therapy (ART) has been successful in dramatically decreasing the morbidity and mortality caused by HIV. This success, coupled with lower-priced drugs, the availability of generic drugs, and an increase in donor funding, has led numerous governments of developing nations to implement treatment programs for their HIV-positive citizens.

The HIV prevalence rate in India is estimated to be less than one percent; however, this translates to over five million HIV-infected individuals, exceeded only by South Africa in terms of the total number of people estimated to be infected by the virus (UNAIDS 2004). In April 2004 the Indian government announced a plan to provide ART in high-prevalence states through public sector health facilities. The program underwent a rapid scale-up and ART is currently being provided in 25 sites around the country. Prior to April 2004, ART was only available in private-sector clinics and in a few public-sector health facilities linked to government agencies or employers that provided workplace health insurance coverage.

A major concern in scaling up ART in resource-limited settings is the potential emergence of drugresistant viral strains. To prevent the emergence of such strains, optimal patient adherence to ART is necessary. Levels of adherence in excess of 95 percent are required to ensure treatment success, adequate viral load suppression, improved immune status, and the slowing of disease progression (Paterson et al. 2000; Ickovics et al. 2002). To date there has been very little scientific data on treatment adherence in India.

It is estimated that 85 percent of new HIV infections in India are the result of sexual transmission (NACO 2004). HIV is spreading beyond high-risk groups to the general population. Women are increasingly affected, comprising one out of four new HIV-positive cases. With increased availability of ART, HIVpositive individuals are living healthier lives and continuing or resuming sexual activity, thus increasing the risk of HIV transmission. There is some evidence from western countries that among populations of men who have sex with men who are on ART, levels of unprotected sex and the incidence of sexually transmitted infections (including HIV) have increased (Chen et al. 2002; Katz et al.2002; Van der Ven et al.2002; Stolte et al.2001; Morbidity Mortality Weekly Report 1999). Optimism related to the success of ART in slowing disease progression, reducing viral load, and improving health status may lead to more risky sexual practices and a possible increase in transmission of infections. Preventive and risky sexual behavior of HIV-positive persons on ART has therefore become an area of special interest and concern.

Findings from exploratory research at sites in Pune and Delhi, India, provide information on these two important issues: adherence to ART and sexual risk behavior among clients on ART. 


\section{Methods}

\section{Objectives}

A team of researchers and service providers conducted a diagnostic study among people living with HIV/AIDS receiving ART at selected private and public sector health facilities in Delhi and Pune. The objectives of the study were to:

- Assess the current levels of adherence to ART among clients.

- Identify the factors that influence adherence to treatment.

- Examine the sexual risk behaviors of clients.

- Determine the economic burden of ART on clients.

\section{Study Design}

The study employed a cross-sectional design. HIV-infected persons receiving ART at selected facilities were interviewed between May and August 2004 as they came in for routine follow-up visits at outpatient clinics (patients admitted in wards were not interviewed). A semi-structured survey questionnaire adapted from adherence instruments developed by the Adult AIDS Clinical Trials Group (AACTG) was used.

Interviews were conducted in Hindi, Marathi, or English, as requested by patients. Trained research interviewers from outside the health facilities conducted the interviews. Ethical approval was obtained from the ethical review board of the Population Council and the management of each participating health facility. Written informed consent

Research Partners

1. Ruby Hall Clinic and Grant Medical Foundation

2. Employees State Insurance Corporation

3. Northern Railway Hospital

4. Institute of Economic Growth, Delhi University

5. Horizons, Population Council was obtained from all participants.

\section{Study Sites}

A convenience sample of four health facilities was selected. In Pune, both a private and a public sector health facility were chosen and in Delhi two public sector facilities were chosen. At the time this study was initiated the national ART program had yet to be implemented. ARVs were only available through private sector clinics, which were treating the majority of HIV-infected persons, and through employerbased health insurance programs, including those administered by public sector health facilities.

The sites participating in the study were:

- Ruby Hall Clinic and Grant Medical Foundation, Pune

- Employees State Insurance Corporation Hospital, Chinchowad, Pune

- Employees State Insurance Corporation Hospital, Jhilmil, New Delhi

- Northern Railway Hospital, New Delhi 


\section{Hgrizons}

Ruby Hall Clinic (RHC) is a private sector health facility providing health care services on a fee-forservice basis. RHC also provides care services to clients from employer-based health insurance programs, such as the Central Government Health Scheme (CGHS) as well as private insurance schemes. Through its charitable arm, the Grant Medical Foundation, RHC provides free health care to a limited number of poor patients.

The Employees State Insurance Corporation (ESIC) is an employer-based, social security organization with a network of health facilities nationwide, including hospitals in Chinchowad and Jhilmil. ESIC falls under the purview of the Indian Ministry of Labor. ESIC provides health care to employees of organizations employing at least 25 people who earn less than Rs. 6000 (US\$140) per month. Organizations covered include small-scale industrial units, export houses, factories, restaurants, security services, and shopping stores. Coverage extends to the families of employees as well as to the workers themselves.

The Indian Railways provides health care to employees and their families through a network of dispensaries and hospitals across the country. This is an employer-based insurance program. Employee cadres include engineers, medical officers, administrative staff, drivers, maintenance crew, lines men, and cleaners. The Northern Railway Hospital (NRH) is the regional referral hospital for railway workers and their families in Delhi and surrounding states in the Northern region.

HIV-positive adult patients who had been on ART for at least 30 days were interviewed. Since small numbers of HIV-infected persons were receiving ART through public sector facilities, all patients receiving ART at ESIC and NRH were invited to participate in the study. At Ruby Hall Clinic, which provided ART to approximately 800 patients at the time of the study, the first 273 clients (34 percent) who came in for follow-up visits were interviewed. The sample size was based on population proportion of 50 percent $(\mathrm{P})$ and confidence level of 90 percent, with absolute precision of 5 percent points (sample size $=\mathrm{z}_{1-\alpha / 2}^{2} \mathrm{P}(1-\mathrm{P}) / \mathrm{d}^{2}$ ) to have sufficient variation in the population characteristics (e.g., sex, education, economic status) that may influence adherence.

Although formal adherence counseling was not provided at any of the sites, physicians at both the private and public sector facilities provided treatment- and adherence-related advice to patients. In the private sector, physicians also discussed the financial implications of long-term ART and assessed patient readiness and ability to continue treatment prior to initiating ART. The provision of support to the patient by the family was encouraged whenever possible at all sites.

\section{Study Population and Recruitment}

The total number of HIV-positive participants who completed interviews in the Delhi and Pune sites was 310. At RHC in Pune 263 participants were interviewed; an additional 10 individuals were asked to participate, but seven withdrew consent and three did not complete the interview because of time constraints; 252 individuals interviewed at RHC paid out-of-pocket for their treatment and 11 had insurance coverage through the CGHS.

As a very small number of clients was receiving ART in the three public sector facilities, all were invited to participate in the study; 47 patients out of a total of 57 on ART ( 82 percent) completed the interview, six did not visit the clinic for a follow-up visit during the recruitment period, and four refused to be 
interviewed. ARVs, routine medical care, and routine monitoring were provided free of cost at NRH and the two ESIC facilities.

\section{Measures}

Adherence was measured using self-reported data. Five measures of adherence were used that reflected different periods of recall:

- Adherence over the past four days.

- Adherence over the past one week.

- The last time a full day's medication was missed.

- The number of times treatment was stopped for more than one week since initiating ART.

- How closely the respondent followed the medication-dosing schedule over the last four days.

The mean 4-day adherence was calculated by dividing the number of pills actually taken by the number of pills prescribed for the four days multiplied by 100 . Higher adherence was defined as a mean 4-day adherence rate of $\geq 90$ percent and lower adherence as a mean 4-day adherence rate of $<90$ percent. Lower adherence for the 4-day period ( $<90$ percent) was the primary outcome measure used in multivariate analysis to determine the independent predictors of adherence. The researchers used a less stringent cut off of $<90$ percent because of emerging evidence suggesting that viral load suppression may be achievable at lower adherence levels with non-nucleoside reverse transcriptase inhibitors (NNRTI) treatment regimens (Maggiolo et al.2005; Weiser et al.2004), which is what the majority of the sample was taking. This level of adherence may also be more realistic for patients to achieve.

\section{Data Analysis}

Chi Square and Kruskall Wallis (non-parametric test) tests were used to assess significance for categorical variables. T-tests and Mann Whitney (non-parametric test) tests were used to assess significance between the groups (e.g., paying for ARVs versus not paying for ARVs) for continuous variables. Independent predictors of lower adherence were determined using logistic regression analysis. A p value of $<.05$ was considered significant.

Researchers explored the factors influencing adherence in this population. Analysis was done at two levels: bivariate analysis using Chi Square tests was done at the first stage to explore associations and to assess significance between individual variables of interest and adherence. This was followed by multivariate analysis using binary logistic regression with significantly related variables to determine the predictors of lower adherence.

\section{Limitations of the Study}

All quantitative data in this report are based on interviews with clients from a convenience sample of health facilities. Although convenience samples cannot be used to generalize to larger populations, the findings reveal important insights into adherence and sexual risk behavior among HIV-infected populations receiving treatment through both private and government health services. 


\section{Hgrizons}

At the time the study was undertaken, the national ARV program had not been initiated and very few patients were receiving ARVs in the public sector. Our sample includes a small number of people receiving free ARVs from the public sector through employer-supported, insurance-based programs (ESIC and NRH). Clients currently accessing ART through the national ART program may come from different socioeconomic backgrounds; nevertheless, the findings provide useful data that are relevant to the scale-up of the national program.

The study did not examine adherence among HIV-infected individuals who may have discontinued treatment or dropped out of the program.

The study used self-reported data to assess adherence. Self-reported adherence has been shown to correlate well with viral load levels (Liu et al. 2001; Duong et al. 2001; Nieuwkerk et al. 2005). However, self-reported data may overestimate adherence; therefore, it is useful to keep in mind that adherence rates may actually be lower than those reported, particularly when higher levels of adherence are reported by patients. When patients report lower levels of adherence, self-reported data is a more accurate measure (Nieuwkerk et al. 2005).

Because the study was cross-sectional, other measures of adherence, such as pill counts and MEMS (i.e., an electronic chip inserted in the lid of the medication bottle that monitors the opening and closing of the lid) were not feasible because patients were not followed over time. 


\section{Results}

\section{Characteristics of the Sample}

Table 1 presents the characteristics of the sample disaggregated by the type of payment for ART: out-ofpocket $(n=252)$ or free through an insurance program $(n=58)$. The majority of patients in the sample were male, employed, and currently married. More than a third had a university education, although a greater proportion of respondents paying out-of-pocket for ART had this level of education compared to those receiving free ART through an insurance program. The mean age of respondents was 37 years (range: 23-70 years). More women were receiving ART at public-sector facilities than at private health facilities. One reason for this is that the employer-based insurance programs operating out of the publicsector facilities extend treatment coverage to families of employees, including spouses. The sample included six couples interviewed at NRH and ESIC, Delhi.

Economic status (ES) was based on ownership of assets. Clients accessing care in the private sector were almost equally distributed across ES quartiles. The quartiles were based on asset scores; quartile one included respondents with the lowest scores and quartile four those with the highest scores. Among clients receiving free ART through insurance programs, the majority were distributed across the first three ES quartiles; very few fell into the highest ES quartile.

Ninety-eight percent of respondents were on a non-protease inhibitor-based treatment regimen. Of these, 88 percent of respondents were on a first-line Nevirapine (NVP)-based regimen (160 on stavudine (D4T)/Lamivudine (3TC)/ NVP and 112 on zidovudine (ZDV) / 3TC / NVP); 7 percent on a first-line Efavirenz (EFV)-based regimen (10 on D4T/3TC/EFV and 12 on AZT/3TC/EFV); and 3 percent on other combinations of didanosine (DDI) and abacavir (ABC). Two percent were taking protease inhibitor-based treatment regimens containing NRTI (nucleoside reverse transcriptase inhibitor) combinations with Ritonavir-boosted Indinavir or Nelfinavir. 


\section{Hgrizons}

Table 1 Background information of study participants $(n=310)$

\begin{tabular}{|c|c|c|c|}
\hline & $\begin{array}{c}\text { Paid out-of-pocket for ART } \\
n=252(\%)\end{array}$ & $\begin{array}{c}\text { Received free ART } \\
n=58(\%)\end{array}$ & $\begin{array}{c}\text { Total } \\
\mathrm{n}=\mathbf{3 1 0}(\%)\end{array}$ \\
\hline \multicolumn{4}{|l|}{ Sex* } \\
\hline Male & $219(87)$ & $42(72)$ & $261(84)$ \\
\hline Female & $33(13)$ & $16(28)$ & $49(16)$ \\
\hline \multicolumn{4}{|l|}{ Age group } \\
\hline Less than 30 years & $38(15)$ & $13(22)$ & $51(16)$ \\
\hline 31 to 45 years & $173(69)$ & $31(53)$ & $204(66)$ \\
\hline More than 45 years & $41(16)$ & $14(24)$ & $55(18)$ \\
\hline \multicolumn{4}{|l|}{ Education* } \\
\hline Less than 5 years of school & $9(4)$ & $21(36)$ & $30(10)$ \\
\hline 6 to 12 years of school & $135(54)$ & $30(52)$ & $165(53)$ \\
\hline University & $108(43)$ & $7(12)$ & $115(37)$ \\
\hline \multicolumn{4}{|l|}{ Employment } \\
\hline Employed & $212(84)$ & $43(74)$ & $255(82)$ \\
\hline Unemployed & $40(16)$ & $15(26)$ & $55(18)$ \\
\hline \multicolumn{4}{|l|}{ Marital status } \\
\hline Currently married & $210(83)$ & $53(91)$ & $263(85)$ \\
\hline Single (never married) & $20(8)$ & $1(2)$ & $21(7)$ \\
\hline Separated/widowed & $22(9)$ & $4(7)$ & $26(8)$ \\
\hline \multicolumn{4}{|l|}{ Economic status* } \\
\hline Quartile 1 & $62(25)$ & $26(45)$ & $88(28)$ \\
\hline Quartile 2 & $54(21)$ & $16(28)$ & $70(23)$ \\
\hline Quartile 3 & $69(27)$ & $12(21)$ & $81(26)$ \\
\hline Quartile 4 & $67(27)$ & $4(7)$ & $77(23)$ \\
\hline \multicolumn{4}{|l|}{ Time since HIV diagnosis } \\
\hline Less than 12 months & $42(17)$ & $13(22)$ & $55(18)$ \\
\hline 13 to 24 months & $60(24)$ & $13(22)$ & $73(24)$ \\
\hline More than 24 months & $150(59)$ & $32(55)$ & $182(59)$ \\
\hline \multicolumn{4}{|l|}{ Time since starting ART } \\
\hline Less than 12 months & $106(42)$ & $22(38)$ & $128(41)$ \\
\hline 13 to 24 months & $70(29)$ & $15(26)$ & $85(27)$ \\
\hline More than 24 months & $76(30)$ & $21(36)$ & $97(31)$ \\
\hline \multicolumn{4}{|l|}{ CD4 at start of ART* } \\
\hline Less than 100 cells & $124(49)$ & $9(17)$ & $133(44)$ \\
\hline 101 to 200 cells & $98(40)$ & $16(30)$ & $114(37)$ \\
\hline More than 200 cells & $30(12)$ & $29(54)$ & $59(20)$ \\
\hline \multicolumn{4}{|l|}{ Current depression* } \\
\hline Minimal & $131(52)$ & $16(28)$ & $147(48)$ \\
\hline Mild & $36(14)$ & $11(19)$ & 47 (15) \\
\hline Moderate & $45(18)$ & $9(15)$ & $54(17)$ \\
\hline Severe & $39(16)$ & $22(38)$ & $61(20)$ \\
\hline
\end{tabular}

Chi square significance $<.01$

Note: Percentages may not add up to 100 because they were rounded up to the nearest whole. 
A majority (59 percent) of study participants were diagnosed with HIV more than 24 months ago and 41 percent had initiated ART in the past 12 months.

National guidelines recommend that ART be initiated when the patient's CD4 count is $\leq 200$ cells $/ \mathrm{mm}^{3}$ or when the patient has been clinically diagnosed with Stage IV disease (WHO classification for disease staging). Treating physicians provided baseline CD4 counts from patient medical records. There was a significant difference in CD4 cell counts and the initiation of ART between those patients who paid outof-pocket and those who received ART for free from their insurance program. Almost half of the paying group initiated ART at an advanced stage of HIV disease (CD4 cell counts $\leq 100$ cells $/ \mathrm{mm}^{3}$ ). In contrast, more than half the patients receiving free ARVs through insurance programs began ART at CD4 cell counts $>200$ cells $/ \mathrm{mm}^{3}$.

Knowledge of the patient's HIV disease and its management was explored. Respondents were asked what they understood about CD4 cell counts for initiating and monitoring treatment; open-ended answers were collected and analyzed qualitatively. Ninety-three percent of respondents noted that a CD4 count test had been done. However, 61 percent of these respondents did not know what the CD4 count measures and 54 percent did not know how it is expected to change with treatment. (Data not shown in table.)

Current depression scores were assessed using the Beck Depression Inventory II (BDI II) (C) 1996 Aaron T Beck. BDI II is a long-standing, validated, and widely used tool to assess current depression over the past week. Overall, almost half the respondents reported minimal depression scores. Nearly a fifth of the patients were severely depressed. Respondents receiving free ART were more likely to report higher depression scores compared to those paying out-of-pocket.

\section{Adherence}

\section{Measures of adherence}

As Table 2 indicates, the mean self-reported four-day adherence for all patients was 93.5 percent. Sixteen percent of respondents reported having missed one or more doses in the last four days.

Over longer periods of recall, reported adherence was lower. Twenty percent of respondents reported missing doses in the past seven days. When respondents were asked about the last time that they missed a full day's dose of medication, 33 percent reported that they had ever missed a full day of medication. Sixteen percent of respondents reported that they had stopped taking their medication for longer than a week at least once since initiating ART. More than a quarter of the respondents reported not having followed the medication schedule over the past four days. There were no significant differences in reported adherence between men and women on any measure of adherence. 


\section{Hgrizons}

Table 2 Self-reported adherence by sex

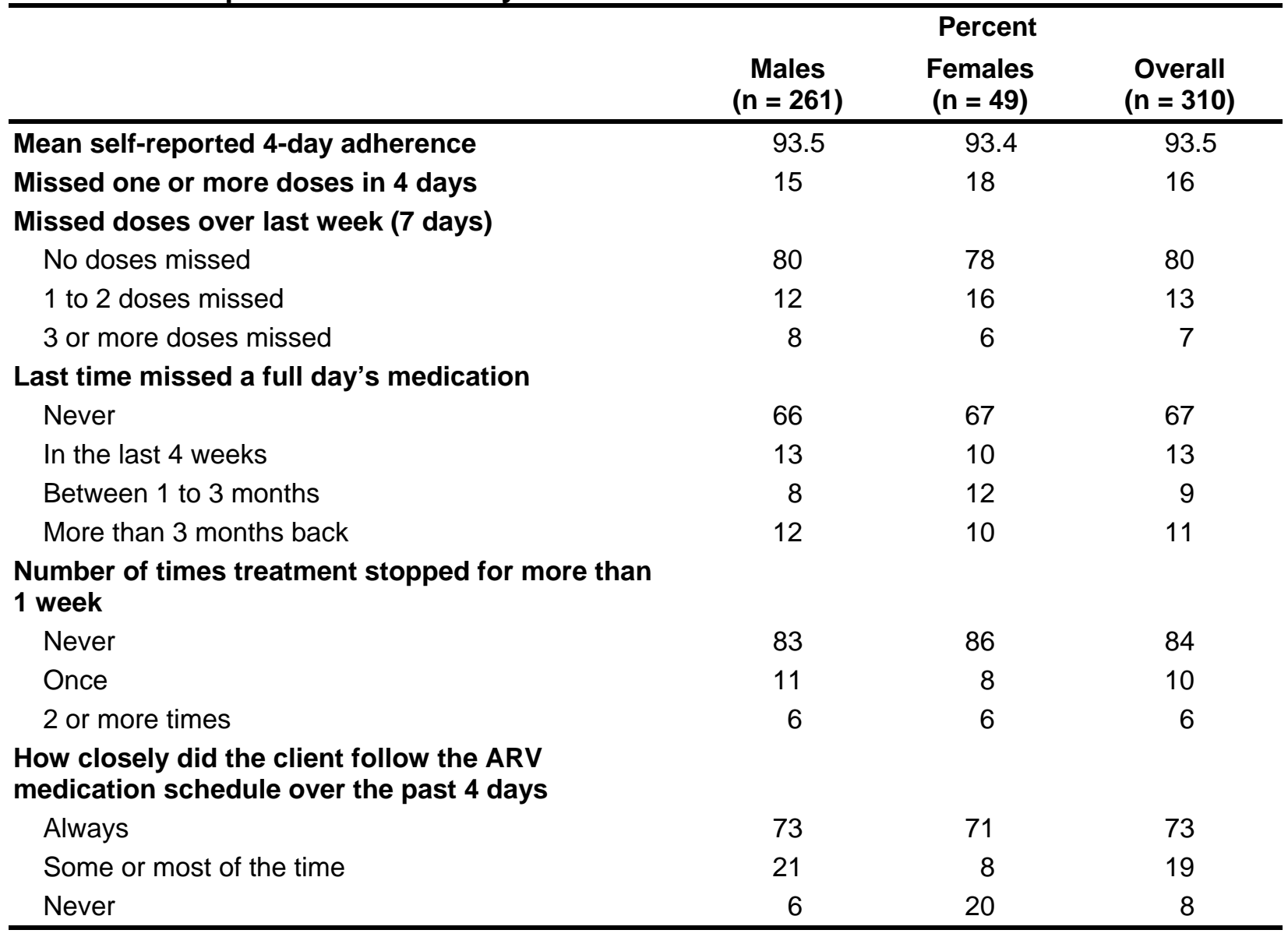

Note: Percentages may not add up to 100 because they were rounded to the nearest whole.

\section{Reasons for missing medications}

Adhering to the dosage schedule: For optimum bioavailability and maximum effect, antiretroviral medications must be taken at regular intervals throughout the day. For example, Triommune (D4T, 3TC, NVP) should be taken every 12 hours. Study participants were asked how well they were able to follow the dosage schedule over the past four days. Seventy-three percent of respondents reported having no problems following the dosage schedule as prescribed by their physician. Nineteen percent of respondents reported following the schedule some of the time and eight percent of respondents reported never following the dosage schedule.

(I often) get delayed by 1-2 hours, but (I have) never taken a double dose, because the doctor said it causes problem. 
I could not take in the morning so took in the afternoon, but never left [forgot to take medicines]. 26-year-old-female

Missed doses over the past week: Twenty percent of respondents $(n=62)$ reported missing doses during the past week. These respondents were asked in open-ended questions to cite reasons for the missed doses; multiple reasons were permitted. The most commonly cited reasons for missing doses over the past week were forgetting to take the medicine ( 38 percent), being away from home ( 34 percent), and running out of pills (26 percent). For 9 of the 19 respondents who reported running out of pills, the reason was public sector dispensary stockouts. Other reasons for missing doses included financial restrictions ( 5 percent), lack of understanding of dosing instructions (4 percent), feeling ill (4 percent), high pill burden ( 2 percent), side effects ( 2 percent), and depression ( 2 percent).

I don't miss my medicines, but I need to remind my wife to take her medications as she gets busy with housework and forgets.

51-year-old male

If medicines are not there [in the dispensary] they tell us to come back. Once or twice they have done so for a week.

32-year-old female accessing services in the public sector

On Mondays, I leave [don't take medicines] because of fasting.

36-year-old female

Missing medications for more than one week: The 51 respondents who reported missing medications for a period of more than a week were asked in open-ended questions to provide reasons for doing so. The most frequently cited reasons were financial difficulties ( 25 percent) and travel away from home (20 percent). Eighty-five percent of patients who reported financial difficulties were paying out-of-pocket for ARVs.

\section{Reasons for regularly taking medications}

Patients who reported never missing medications were asked to elaborate in open-ended questions on their reasons for regularly taking their medication. The most commonly cited reason was a desire to be healthy and avoid illness. In addition, a doctor's advice and emphasis on taking medications regularly (mostly mentioned by private sector patients) were important factors. Many respondents indicated that they had a desire to live for their families and that family support was very important for taking medications regularly. The cost of treatment and the money invested in the respondents' health was another important reason for adhering to medications. Respondents also viewed adherence as a means of preventing frequent illnesses and some viewed adherence as a cost-saving mechanism.

I have not missed any pill from the day I started taking medicines. You can see that all those patients who were having illness are no more and here I am working hard and sitting healthy in front of you. 


\section{Hgrizons}

I want to be alive for my wife and children. I should be hopeful as research is going on, something will come up.

37-year-old male

As the doctor told me that if you are going to take it regularly then only it will work. Before I used to get some or the other health problem like fever and treating that was (more) expensive compared to this.

39-year-old male

\section{Reported side effects}

Many ARVs have associated side effects that can be either temporary in nature (three to four weeks) or more permanent, which often require a change of medication. Study participants were asked to report on symptoms related to side effects experienced in the past 30 days and to grade them according to their severity on a scale of 0 to 3 ( 0 : none reported; 1 : present but not bothersome; 2 : present and mildly to moderately bothersome; 3 : present and severely bothersome). Twenty commonly experienced side effects adapted from a validated and widely used AACTG questionnaire were listed (NIAID AACTG Symptoms Distress Module).

As Table 3 illustrates, the most frequently reported symptoms were numbness or tingling in the hands and feet (42 percent), changes in body and face appearance (lipoatrophy/lipodystrophy; 38 percent), fatigue or loss of energy (38 percent), skin rashes (36 percent), muscle aches and joint pains (35 percent), and feelings of depression ( 35 percent). Of those who reported symptoms, less than 12 percent reported them to be severe. Fatigue or loss of energy was most often reported as severely bothersome. 
Table 3 Self-reported symptoms related to side effects $(n=310)$

\begin{tabular}{lcc}
\hline Side effects & $\begin{array}{c}\text { \% reported } \\
\text { by patients }\end{array}$ & $\begin{array}{c}\text { \% reporting } \\
\text { them as severely } \\
\text { bothersome* }\end{array}$ \\
\hline Neurological/mood & 22 & 12 \\
$\quad$ Dizziness/lightheadedness & 42 & 13 \\
Pain/numbness/tingling in limbs & 21 & 11 \\
$\quad$ Memory loss & 35 & 5 \\
$\quad$ Feeling sad, down, depressed & 22 & 12 \\
$\quad$ Anxiety/nervousness & 26 & 8 \\
$\quad$ Sleep disturbances & 21 & 11 \\
Gastrointestinal & 20 & 8 \\
$\quad$ Nausea/vomiting & 25 & 11 \\
Diarrhea & 27 & 3 \\
Loss of appetite/taste & & 5 \\
$\quad$ Bloating/pain in abdomen & 36 & 12 \\
Connective tissue and skin & 16 & 12 \\
$\quad$ Skin rash, dryness, or itching & 35 & 4 \\
Hair loss or change in way hair looks & & \\
Muscle aches and joint pains & 24 & 2 \\
Respiratory & & 6 \\
$\quad$ Cough or breathlessness & 38 & 12 \\
Bodily changes & 29 & 6 \\
$\quad$ Changes in body/face looks - fat loss or gain & & 19 \\
$\quad$ Problems with wasting or weight loss & 27 & 13 \\
General & 25 & \\
$\quad$ Headache & 38 & \\
Sexual problems: loss of desire or satisfaction & 23 & \\
Fatigue or loss of energy & & \\
Fever chills or night sweats & & \\
\hline
\end{tabular}

${ }^{*}$ Of those who reported the side effect

Note: Percentages may not add up to 100 because they were rounded to the nearest whole

As noted above, each side effect was scored on a four-point scale (0 to 3 ) and a total score was calculated for each patient. The mean score for all patients was 8.27 (range 0 to 60). Overall, 9 percent of patients reported no side effects (a score of 0 ), 80 percent had low scores (1-20), 9 percent had moderate scores (21-40), and only 2 percent had high scores (41-60). As Figure 1 illustrates, there were no significant differences in scores between patients on ART for different periods of time $(p=.330)$. 
Figure 1 Side effect scores reported by patients on ART

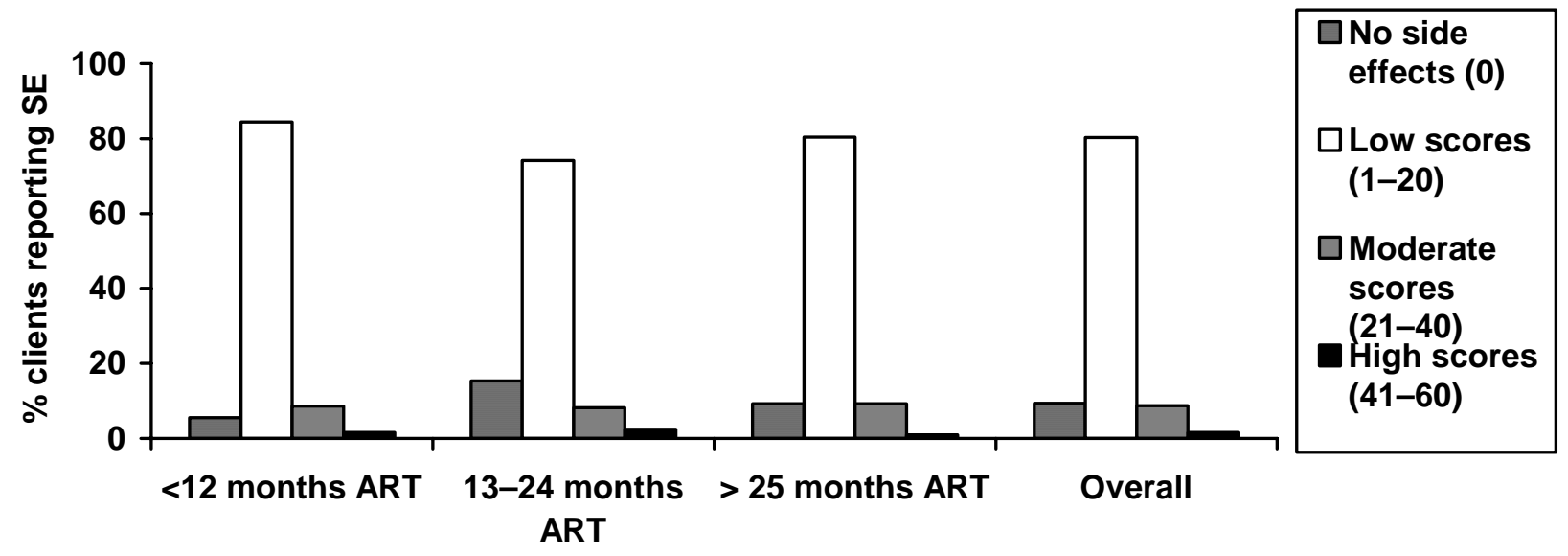

Kruskall Wallis test; $p>.05$

Because side effects are expected in the first few months after initiating ART, we explored differences in reported side effects between the time periods of $<6$ months, $7-12$ months, $13-24$ months, and $\geq 25$ months and still found no differences.

Women respondents reported significantly higher mean scores for side effects than men (13.57 versus 7.27; $\mathrm{p}<0.001)$. Respondents receiving free ARVs reported significantly higher mean scores compared to those paying out-of-pocket for ARVs (18.03 versus 6.02; $\mathrm{p}<0.01)$.

An association was found between side effect scores and disease stage (as defined by CD4 counts). The highest mean scores were reported by patients who started ART with CD4 counts $>201 \mathrm{cells} / \mathrm{mm}^{3}$; lower side effects scores were reported by patients starting ART at CD4 cell counts between $101-200$ cells $/ \mathrm{mm}^{3}$ and below 100 cells $/ \mathrm{mm}^{3}$ (12.66 versus 8.10 versus $\left.6.47 ; \mathrm{p}<.01\right)$.

\section{Associations between adherence and sociodemographic chacteristics, and HIV disease- and ART-related variables}

The effect of a number of factors thought to be associated with ARV adherence was explored through bivariate analysis (Table 4). The study found that respondents with a university education were more likely to report higher adherence (mean 4-day adherence of $\geq 90$ percent); respondents with less than five years of education were more likely to report lower adherence levels (mean 4-day adherence of $<90$ percent).

Unemployed respondents were more likely to report lower adherence compared to those who were employed. Respondents receiving free ART through insurance-based programs were also more likely to report lower adherence compared to those who paid out-of-pocket. Interestingly, economic status was not found to be associated with adherence. 
The time since diagnosis of HIV was not associated with adherence. The study also found no significant differences between respondents' adherence levels and the duration of time on ART. Researchers were concerned that adherence levels would decrease among patients who had been on ART for longer periods of time.

Patients who initiated ART when they had advanced HIV disease (defined as CD4 cell counts $<100$ cells $/ \mathrm{mm}^{3}$ ) were more likely to report higher adherence compared to respondents who initiated ART at higher CD4 cell counts.

The study found that patients who reported being hospitalized two or more times in the past 12 months were more likely to report lower adherence compared to those who had been hospitalized once or not at all.

Depression levels were found to be associated with adherence. Patients who reported moderate to severe depression were more likely to report lower adherence compared to respondents with minimal or mild depression.

Taking fixed-dose combinations (FDC) in which all three ARV medications are combined into a single pill has been thought to enhance patient adherence to the treatment regimen. In India first-line treatment regimens are freely available and are the cheapest in the market (e.g., Triommune: D4T, 3TC, NVP; Duovir-N: AZT, 3TC, NVP). The majority of the study patients ( 84.5 percent) were taking a FDC with three first-line medications in one preparation. Taking FDCs, however, was not associated with higher adherence.

As almost all patients (98 percent) were on a non-protease-inhibitor-containing treatment regimen, this variable was not analyzed further.

The study collected self-reported data on the number of medications (both ARVs and non-ARVs) respondents were taking. Patients who were taking more than 7 pills/day were more likely to report lower adherence when compared to patients taking between 2 to 6 pills /day or $<2$ pills /day, but the differences were not statistically significant ( 13 percent versus 16 percent versus 24 percent; $p=0.40$ ). Respondents who had moderate to severe side effects were significantly more likely to report lower adherence than those who reported no or mild side effects.

Overall, 54 percent of the respondents knew the names of the medications that they were taking. For those individuals who were unable to identify their medications, their physicians' offices provided confirmation of the drug regimen or information was ascertained from the medicine packaging. Those who knew the names of their medications were more likely to report higher adherence than those who did not know what they were taking ( 59 percent versus 44 percent, $\mathrm{p}=0.051$ ).

The study also explored the associations between alcohol use, drug use, and ART adherence. Lower adherence was found among those who had consumed alcohol in the past 30 days but the association was not significant. Eleven respondents reported ever using drugs and six respondents reported active drug use (in the past six months). Three of the six individuals reporting active drug use also reported lower adherence. Because of the small numbers further analysis was not conducted with this variable. 


\section{Hgrizons}

Table 4 Association of sociodemographic, HIV disease-, and ART-related variables with adherence (bivariate analysis)

\begin{tabular}{|c|c|c|c|}
\hline & $\begin{array}{c}\text { Higher adherence } \\
(\geq 90 \%) \\
(\mathrm{n}=261) \\
\end{array}$ & $\begin{array}{c}\text { Lower adherence } \\
(<90 \%) \\
(\mathrm{n}=49) \\
\end{array}$ & Significance* $^{\star}$ \\
\hline \multicolumn{4}{|l|}{ SOCIODEMOGRAPHIC VARIABLES } \\
\hline \multicolumn{4}{|l|}{ Age group } \\
\hline Less than 30 years $(n=51)$ & 71 & 29 & 0.011 \\
\hline 31 to 45 years $(n=204)$ & 88 & 12 & \\
\hline More than 45 years $(n=55)$ & 84 & 16 & \\
\hline \multicolumn{4}{|l|}{ Education } \\
\hline Less than 5 years of school $(n=30)$ & 73 & 27 & 0.008 \\
\hline 6 to 12 years of school $(n=165)$ & 81 & 19 & \\
\hline University $(n=115)$ & 92 & 8 & \\
\hline \multicolumn{4}{|l|}{ Employment } \\
\hline Employed $(\mathrm{n}=255)$ & 87 & 13 & 0.010 \\
\hline Unemployed $(n=55)$ & 73 & 27 & \\
\hline \multicolumn{4}{|l|}{ Economic status } \\
\hline Quartile 1 (n = 88) & 81 & 19 & 0.558 \\
\hline Quartile $2(n=70)$ & 83 & 17 & \\
\hline Quartile $3(n=81)$ & 85 & 15 & \\
\hline Quartile $4(n=71)$ & 89 & 11 & \\
\hline \multicolumn{4}{|l|}{ Social support from family } \\
\hline Yes $(n=285)$ & 85 & 15 & 0.529 \\
\hline No $(n=25)$ & 80 & 20 & \\
\hline \multicolumn{4}{|l|}{ Type of payment for ART } \\
\hline Paid out of pocket $(n=252)$ & 89 & 11 & 0.000 \\
\hline Obtained free $(n=58)$ & 60 & 40 & \\
\hline \multicolumn{4}{|l|}{ HIV DISEASE-RELATED VARIABLES } \\
\hline \multicolumn{4}{|l|}{ Time since HIV diagnosis } \\
\hline Less than 12 months $(n=55)$ & 84 & 16 & 0.971 \\
\hline 13 to 24 months $(n=73)$ & 84 & 16 & \\
\hline More than 24 months $(n=182)$ & 85 & 15 & \\
\hline \multicolumn{4}{|l|}{ Time since starting ART } \\
\hline Less than 12 months $(n=128)$ & 82 & 18 & 0.512 \\
\hline 13 to 24 months $(n=85)$ & 84 & 16 & \\
\hline More than 24 months $(n=97)$ & 88 & 12 & \\
\hline \multicolumn{4}{|l|}{ CD4 count at start of ART } \\
\hline Less than 100 cells $/ \mathrm{mm}^{3}(n=133)$ & 89 & 11 & 0.001 \\
\hline 101 to 200 cells $/ \mathrm{mm}^{3}(\mathrm{n}=114)$ & 86 & 14 & \\
\hline More than 200 cells $/ \mathrm{mm}^{3}(n=59)$ & 68 & 32 & \\
\hline
\end{tabular}


Table 4 Association of sociodemographic, HIV disease-, and ART-related variables with adherence (bivariate analysis) (continued)

$\begin{array}{llll}\begin{array}{l}\text { Number of hospitalizations due to } \\ \text { HIV-related illness }\end{array} & & & \\ \text { Never }(n=235) & 85 & 15 & 0.011 \\ \text { Once }(n=58) & 88 & 12 & \\ \text { Two or more times }(n=17) & 59 & 41 & 0.000 \\ \text { Depression } & & 7 & \\ \text { Minimal }(n=147) & 93 & 17 & \\ \text { Mild }(n=47) & 83 & 17 & \\ \text { Moderate }(n=54) & 83 & 34 & \\ \text { Severe }(n=61) & 66 & \end{array}$

\begin{tabular}{|c|c|c|c|}
\hline \multicolumn{4}{|l|}{ ART-RELATED VARIABLES } \\
\hline \multicolumn{4}{|l|}{$\begin{array}{l}\text { Medication burden } \\
\text { (Number of all medications) }\end{array}$} \\
\hline One medication $(\mathrm{n}=117)$ & 88 & 12 & 0.003 \\
\hline $2-3$ medications $(n=136)$ & 87 & 13 & \\
\hline 4 or more medications $(n=56)$ & 70 & 30 & \\
\hline \multicolumn{4}{|l|}{ ART regimen } \\
\hline Fixed-dose combination $(n=262)$ & 84 & 16 & 0.569 \\
\hline Non-FDC $(n=47)$ & 89 & 11 & \\
\hline \multicolumn{4}{|l|}{ Total pill burden } \\
\hline 2 or fewer pills/d $(n=119)$ & 87 & 13 & 0.409 \\
\hline $3-6$ pills/d $(n=166)$ & 84 & 16 & \\
\hline 7 or more pills/d $(n=25)$ & 76 & 24 & \\
\hline \multicolumn{4}{|l|}{ Side effects } \\
\hline None to low scores $(n=278)$ & 87 & 13 & 0.000 \\
\hline Moderate to high scores $(n=32)$ & 56 & 44 & \\
\hline \multicolumn{4}{|l|}{ Knowledge of medication } \\
\hline Knew medications $(n=166)$ & 88 & 12 & 0.051 \\
\hline Did not know medications $(n=144)$ & 80 & 20 & \\
\hline \multicolumn{4}{|l|}{ Alcohol use } \\
\hline Yes $(n=47)$ & 74 & 26 & 0.060 \\
\hline No $(n=255)$ & 86 & 24 & \\
\hline \multicolumn{4}{|l|}{ Ever drug use } \\
\hline Yes $(n=11)$ & 55 & 45 & $0.018^{* *}$ \\
\hline No $(n=299)$ & 85 & 15 & \\
\hline
\end{tabular}

${ }^{*}$ Chi Square Test

**Fishers exact test

Note: Percentages rounded to the nearest whole. 


\section{Hgrizons}

\section{Predictors of lower adherence}

To determine the independent predictors of lower adherence (mean 4-day adherence of $<90$ percent), multivariate analysis using logistic regression was performed. Variables found to be significantly associated with adherence outcomes in the bivariate analysis were included.

The following variables were found to be significantly associated with lower adherence on bivariate analysis and were included in the multivariate analysis: education, employment status, CD4 counts, number of hospitalizations, medication burden, source of funding for ARV medications, depression, and side effects.

Based on the multivariate analysis, severe depression and obtaining free ARVs were found to be significantly associated with lower adherence. Patients with severe depression were four and a half times more likely to report lower adherence compared to those with minimal depression $(\mathrm{OR} 4.5 ; 95 \% \mathrm{CI}=$ 1.639-12.269, $\mathrm{p}=0.003)$. Patients receiving free ARVs were four times more likely to report lower adherence compared to patients paying out-of-pocket for their treatment (OR 4.0; 95\% CI $=1.422-$ $11.542, \mathrm{p}=.009)$.

\section{Method of payment for ART}

The method of payment for ART as an independent predictor of lower adherence was further analyzed. As Table 5 shows, the mean four-day adherence was significantly lower among patients receiving free ART through an insurance program compared to those paying out-of-pocket for treatment. Adherence was significantly lower among patients receiving free ARVs on all self-reported measures of adherence. 
Table 5 Self-reported adherence by method of payment

\begin{tabular}{|c|c|c|c|}
\hline & $\begin{array}{c}\text { Out-of-pocket ART } \\
n=252 \\
\%\end{array}$ & $\begin{array}{c}\text { Free ART } \\
\mathrm{n}=\mathbf{5 8} \\
\%\end{array}$ & Significance \\
\hline Mean 4-day adherence & 96 & 81 & $0.001^{*}$ \\
\hline Missed one or more doses over last 4 days & 11 & 40 & $0.000 * *$ \\
\hline \multicolumn{4}{|l|}{ Missed doses over last week (7 days) } \\
\hline No doses missed & 86 & 57 & $0.000^{* *}$ \\
\hline 1 to 2 doses missed & 11 & 19 & \\
\hline 3 or more doses missed & 4 & 24 & \\
\hline \multicolumn{4}{|l|}{ Last time missed a full day's medication } \\
\hline Never & 72 & 41 & $0.000^{* *}$ \\
\hline In the last 4 weeks & 9 & 31 & \\
\hline Between 1 to 3 months ago & 9 & 10 & \\
\hline More than 3 months back & 10 & 17 & \\
\hline \multicolumn{4}{|l|}{$\begin{array}{l}\text { Number of times treatment stopped for more } \\
\text { than } 1 \text { week }\end{array}$} \\
\hline Never & 88 & 66 & $0.000^{\star *}$ \\
\hline Once & 8 & 21 & \\
\hline 2 or more times & 4 & 14 & \\
\hline \multicolumn{4}{|l|}{$\begin{array}{l}\text { How closely did respondent follow ARV } \\
\text { medication schedule }\end{array}$} \\
\hline Always & 81 & 40 & $0.000^{* *}$ \\
\hline Most of the time & 14 & 17 & \\
\hline Some of the time & 3 & 12 & \\
\hline Never & 3 & 31 & \\
\hline
\end{tabular}

Note: Percentages may not add up to $100 \%$ since percentages were rounded to the nearest whole *T-Test and Mann Whitney U

${ }^{* *}$ Chi Square Test

As Figure 2 shows, the mean four-day self-reported adherence was significantly lower among patients receiving free ART across the first three quartiles of economic status. Statistical analysis was not done for the highest economic status quartile because very few patients in this group accessed free ARVs (see Table 1, page 12). 


\section{Hgrizons}

Figure 2 Mean 4-day adherence by economic status quartiles

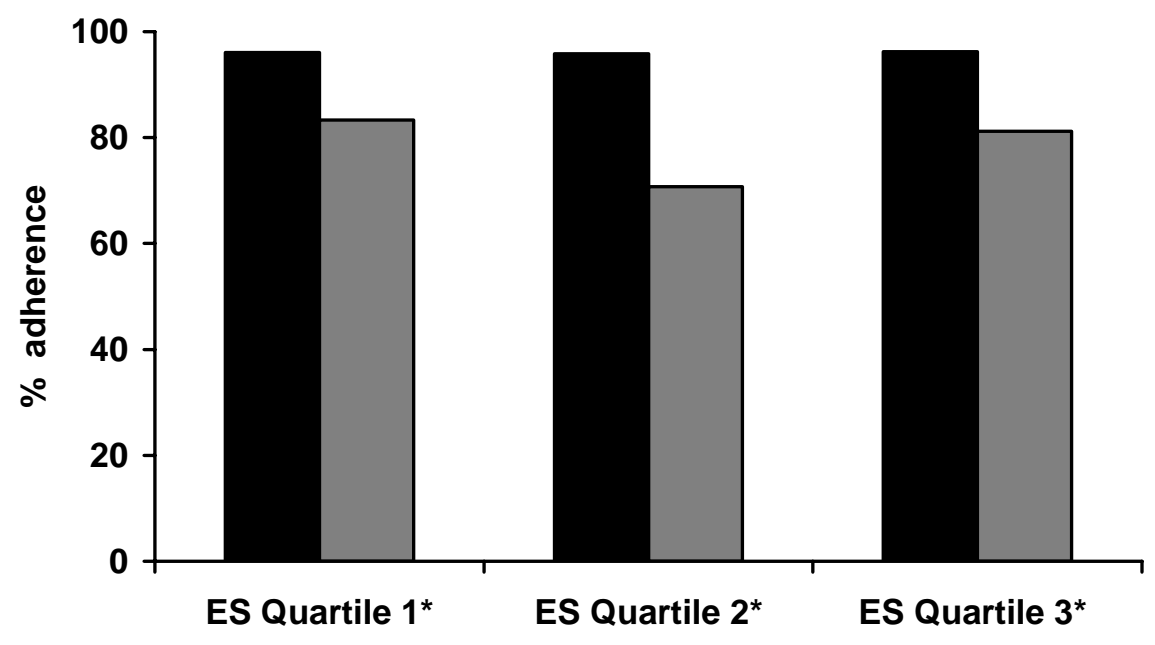

Paid out-of-pocket

DFree ART

*T test and Mann Whitney $U, p<.01$

The researchers examined adherence levels with regard to type of payment for ART and economic status. Using logistic regression analysis to control for economic status, the type of payment (out-of-pocket vs. insurance coverage) was found to be significantly associated with adherence. Patients receiving free ART through an insurance-based program were five times more likely to report lower adherence (mean 4-day adherence of $<90$ percent) compared to those paying for ART. There was no association between economic status and adherence.

\section{Economic Aspects of Treatment}

Economic factors, including the cost of treatment and financing mechanisms to pay for treatment, can influence adherence and are important in India, given that between 75 and 85 percent of health care is delivered in the private sector. In this study, the majority of respondents $(n=252)$ accessed care in the private sector where they paid entirely out-of- pocket for antiretroviral medications and laboratory tests each time they accessed services. Forty-seven respondents received care from the public sector through employer-supported health insurance programs; no money was paid at the time of accessing services, including for medications and laboratory monitoring. A few respondents $(n=11)$ had employer-supported insurance coverage that allowed them to access care in the private sector where they paid money at the time of obtaining services and received reimbursement for all expenditures upon submission of bills.

The researchers explored the financial aspects of treatment among all participants by asking about the amount spent on ART, sources of financing for treatment, and the potential impact of the long-term costs of ART on the household and on treatment adherence. 


\section{Costs of treatment}

The average monthly amount spent out of pocket on treatment (ARVs and diagnostics) was Rs 3,570 for all respondents in the sample $(n=310)$. For those who had no insurance coverage $(n=252)$ this amount was higher (Rs 4,376). A large proportion of respondents (43 percent) reported spending on average between Rs 500 to 2,000 per month and a quarter reported spending between Rs 2,000 to 3,000 per month (Table 6).

Table 6 Percent distribution of monthly costs $(n=310)$

\begin{tabular}{lc}
\hline Amount of money (Indian Rupees) & Percent \\
\hline Rs 0 to 500 & 19 \\
Rs 501 to 2,000 & 43 \\
Rs 2001 to 3,000 & 24 \\
Rs 3001 to 4,000 & 4 \\
> Rs 4,001 & 10 \\
\hline
\end{tabular}

Note: Rs $43=$ US\$1

Monthly expenditure on drugs for the entire sample was on an average Rs 1,775. For those without insurance coverage who were paying out-of-pocket the average monthly cost was Rs 2,159. Expenditure on diagnostic tests was as important as expenditure on ARV medications. The average monthly expenditure on laboratory diagnostics (routine monitoring tests, and HIV specific monitoring tests, such as CD4 counts and viral load) for all respondents was Rs 1,815 and was Rs 2,217 for those without insurance coverage. These figures indicate a major financial burden for those paying out-of-pocket for drugs and tests, especially for those patients who have no insurance coverage at all.

Respondents were asked about expenditures incurred prior to initiating ART. Eighty-six percent of respondents reported they had to pay out-of-pocket for laboratory tests and other diagnostics before initiating ART. Respondents without insurance coverage reported an average expenditure of Rs 5,544 compared to Rs 1,339 reported by respondents with insurance coverage. Paying for initial diagnostics can be a large financial burden (Gupta and Sankar 2000) even for persons able to access free ART.

Study participants were asked about expenditures incurred for various laboratory tests in the past month. As shown in Table 7, 25 percent and 98 percent of respondents underwent viral loads and CD4 tests, respectively. The high cost of the viral load test may explain why fewer patients had this test. Given the high proportion of respondents who reported having had a CD4 count in the past month and the relatively large proportion whose costs were not fully covered, this monitoring test constitutes a large burden of the laboratory monitoring costs. 


\section{Hgrizons}

Table 7 Average out of pocket expenses for diagnostics and ARVs in the past month

\begin{tabular}{lccc}
\hline Diagnostics & $\begin{array}{c}\text { \% reporting tests } \\
(\mathbf{n}=\mathbf{3 1 0})\end{array}$ & $\begin{array}{c}\text { \% whose costs } \\
\text { were not fully } \\
\text { covered* }\end{array}$ & $\begin{array}{c}\text { Average out-of- } \\
\text { pocket costs, if not } \\
\text { fully covered (Rs) }\end{array}$ \\
\hline 1. Routine laboratory tests & 18 & 60 & 902 \\
2. CD4 test & 98 & 84 & 1,839 \\
3. Viral load & 25 & 86 & 4,741 \\
4. X-ray, radiological investigations & 9 & 47 & 1,193 \\
5. All diagnostic tests & & & 2,217 \\
6. ARV medications & & & 2,159 \\
7. Total cost of treatment (5+6) & & & 4,376 \\
\hline
\end{tabular}

${ }^{*}$ Of those who reported having had the test

On average, respondents paid Rs 2,217 out-of-pocket for all diagnostic tests in the last month. The average monthly out-of-pocket cost of being on ART was Rs 4,376, which was equally divided between the cost of medications and the cost of laboratory monitoring. The combined cost of laboratory diagnostics and medication can place a significant economic burden on individuals and the household.

\section{Source of financing for treatment}

Respondents were asked about the source of financing for their treatment; multiple responses were permitted. A substantial proportion of respondents reported using their savings (43 percent) or their current earnings ( 37 percent) to finance their treatment (Table 8). A third of respondents reported receiving support from the family. Ten percent of respondents reported borrowing, which has the potential of burdening households and individuals with debt.

Table 8 Source of financing for ARV medications $(n=310)$

\begin{tabular}{lc}
\hline Source & Percent \\
\hline Savings & 43 \\
Salary & 37 \\
Family & 33 \\
Insurance (ESIC/NRH/CGHS) & 18 \\
Borrowing & 10 \\
Sale of assets & 3 \\
Other (e.g., personal insurance, NGO) & 4 \\
\hline
\end{tabular}




\section{Economic burden of ART}

Study participants were asked how the economic burden of ART would impact their lives in the future; multiple responses were permitted. As shown in Table 9, more than half reported that it would deplete their personal savings and nearly a third reported that they would have to increase their borrowing. Nearly half the respondents said that continued expenditure on ART would impact the amount they could spend on housing and utilities, a quarter said it would reduce the amount they could spend on food, and a fifth reported that it would negatively impact their children's schooling.

Table 9 Effect of economic burden of ART on other aspects of life $(n=310)$

\begin{tabular}{lc}
\hline & Percent \\
\hline Depletion of savings & 59 \\
Less money for utilities and housing & 45 \\
Increased borrowing & 31 \\
Less money available to provide financial support to other family members & 30 \\
Less money for food & 25 \\
Less money for children's schooling & 20 \\
Sale of assets & 15 \\
\hline
\end{tabular}

\section{Life-long commitment to ARVs}

Respondents were asked about their commitment to taking ARVs for the rest of their lives. Sixty-four percent of respondents said that they would be able to continue taking ARVs for the long-term. The most frequently cited reasons were to live longer, to care and provide for their families, and to be well in order to pay for the medications. Around a third of respondents were unsure of their ability to continue due to the uncertainty of their employment and financial situations. Less than four percent said that they didn't think they would be able to continue taking the medications in the long term mainly because of financial constraints.

I have to increase my life span to complete those incomplete tasks. Every one will die one day. What will other people say if I die before my parents. I have to look after my brother's children too. 35 -year-old male client accessing services in the private sector

I get interest from the money I saved and I can spend it so I feel I will always be able to take the medicine.

35-year-old male client accessing services in the private sector

[I'm not sure I will be able to], I have no income source; I am totally dependent on others. 33 -year-old male client accessing care in the private sector 


\section{Hgrizons}

[I am not sure] they give medicines for so long... will get tired of taking them [for so long]

25- year-old female client accessing services in the public sector and covered by insurance

Patients paying out-of-pocket for ART at Ruby Hall Clinic were asked whether they would move to a government facility when free ARVs became available through the national program. Seventy-one percent of respondents said that they would move primarily for financial reasons. Ten percent of respondents were unsure if they would move to a government facility. Around 19 percent said that they would not move to a government facility to receive free ARVs. The main reasons these respondents $(\mathrm{n}=$ 70) indicated that they wouldn't switch to the public sector were concerns about confidentiality (34 percent), fear of poor quality of care and medications (30 percent), and trust in their current physician (7 percent).

Yes [I will move] I can save that much money and use it for my children's future.

35-year-old male

Yes [I will move], if the medicines of that company are standard, then I will take. Otherwise no.

34-year-old male

No [I will not move] I do not trust the quality of medicines.

55-year-old male

No [I will not move] they will not follow secrecy.

40-year-old male

\section{Sexual Behavior}

This study explored the sexual behavior of respondents and their relationships with regular partners and casual partners within the last six months. Male respondents were also asked about sexual activity with sex workers and male sex partners. Although they were receiving ART, four respondents (three women and one man) were not included in the analysis on sexual behavior because they were not aware of their HIV status. These respondents reported that their respective families were told of their illness.

Key themes of analysis were type of partners, knowledge of partner status, disclosure of own HIV status to partners, condom use at last sex, and consistent condom use.

\section{Reported sexual activity in the past six months}

As per national guidelines ART is initiated by HIV-positive patients with CD4 cell counts of less than 200 cells $/ \mathrm{mm}^{3}$ or when they are in Stage IV of HIV disease (WHO classification for disease staging). At this point, patients can be quite sick and many will have experienced one or more episodes of opportunistic infections. Once patients begin ART their immune systems and health status improve, and many are able to engage in sexual activity. Researchers explored the factors influencing sexual activity among respondents. 
As Table 10 shows, 61 percent of respondents reported having had sex during the reference period. Not surprisingly, marital status was strongly associated with reporting sex; married respondents reported sexual activity more often than single or separated/divorced/widowed respondents.

Disease stage at the start of ART, based on CD4 counts, was found to be associated with reported sexual activity. Patients who had initiated ART with advanced HIV disease (CD4 cell counts $<100$ cells $/ \mathrm{mm}^{3)}$ were significantly less likely to report sexual activity in the past six months compared to respondents who had initiated ART with higher CD4 cell counts $(\mathrm{p}=0.037)$. Study participants with moderate to severe depression were less likely to report sexual activity in the past six months compared to those with minimal depression.

Age, time since HIV diagnosis, and duration on ART were not associated with respondents' sexual activity during the reference period. 


\section{Hgrizons}

Table 10 Self-reported sexual activity in the past 6 months

\begin{tabular}{|c|c|c|}
\hline & $\begin{array}{l}\text { \% reporting sex } \\
\text { in past } 6 \text { months } \\
(n=187)\end{array}$ & Significance* \\
\hline \multicolumn{3}{|l|}{ Sex } \\
\hline Male $(n=260)$ & 61 & .771 \\
\hline Female $(n=46)$ & 63 & \\
\hline \multicolumn{3}{|l|}{ Age } \\
\hline Less than 30 years $(n=49)$ & 63 & .646 \\
\hline 31 to 45 years $(n=203)$ & 62 & \\
\hline More than 46 years $(n=54)$ & 56 & \\
\hline \multicolumn{3}{|l|}{ Marital status } \\
\hline Currently married $(n=260)$ & 69 & .000 \\
\hline Single (never married) $(n=21)$ & 33 & \\
\hline Separated/divorced/widowed $(n=25)$ & 8 & \\
\hline \multicolumn{3}{|l|}{ Time since HIV diagnosis } \\
\hline Less than 12 months $(n=55)$ & 62 & .436 \\
\hline 13 to 24 months $(n=73)$ & 67 & \\
\hline More than 24 months $(n=178)$ & 58 & \\
\hline \multicolumn{3}{|l|}{ Time since starting ART } \\
\hline Less than 12 months $(n=125)$ & 62 & .578 \\
\hline 13 to 24 months $(n=85)$ & 57 & \\
\hline More than 24 months $(n=96)$ & 64 & \\
\hline \multicolumn{3}{|l|}{ CD4 count at start of ART } \\
\hline Less than 100 cells $/ \mathrm{mm}^{3}(n=133)$ & 53 & .037 \\
\hline 101 to 200 cells $/ \mathrm{mm}^{3}(\mathrm{n}=113)$ & 66 & \\
\hline More than 200 cells $/ \mathrm{mm}^{3}(n=56)$ & 70 & \\
\hline \multicolumn{3}{|l|}{ Depression } \\
\hline Minimal $(n=147)$ & 70 & .015 \\
\hline Mild $(n=45)$ & 62 & \\
\hline Moderate $(n=54)$ & 46 & \\
\hline Severe $(n=59)$ & 54 & \\
\hline
\end{tabular}

Note: Percentages rounded off to nearest whole

${ }^{*}$ Chi square test

\section{Type of partners}

Respondents who reported sexual activity in the past six months $(\mathrm{n}=187)$ were asked about the different types of partners they had sex with during the reference period. A regular partner was defined as a spouse, someone with whom the respondent lived, or a stable, steady partner. A non-regular or casual partner was 
defined as a partner the respondent was not living with, married to, and rarely had sex with. A sex worker was defined as a partner the respondent paid money or gave gifts to in exchange for sex.

Ninety-six percent (180 of 187) of respondents who reported being sexually active in the past six months reported having sexual intercourse with a regular partner. Only four percent ( 8 of 187) of respondents reported having had sexual intercourse with a casual partner and two percent ( 3 of 187) with a sex worker. All the respondents who reported sex with a casual partner or a sex worker were male.

Male respondents were also asked whether they had sex with a male partner. Three of the 158 sexually active male respondents reported ever having sex with a male partner; none reported sex with a male partner during the reference period.

\section{Regular partner relationships}

Because the majority of respondents reported sexual activity with a regular partner, these relationships were explored in greater detail.

Knowledge of HIV status of regular partners: Partner status reported here is based on patient report; HIV testing was not conducted. Respondents were asked whether or not they knew the HIV status of their regular partner. Overall 83 percent of respondents who reported sex with a regular partner reported knowing their partner's HIV status. Forty-three percent reported an HIV-positive partner, 40 percent an HIV-negative partner, and 17 percent reported not knowing their partner's HIV status.

Statistically significant differences were seen between men and women $(\mathrm{p}<.001)$. As Figure 3 shows, more men reported an HIV-negative partner than women (45 percent versus 11 percent) and more men reported not knowing their partner's HIV status compared to women (18 percent versus 14 percent). More women reported having an HIV-positive regular partner ( 75 percent versus 38 percent). These findings reflect current trends in India of Indian women being predominantly infected by their spouses/regular partners (NACO 2002). 
Figure 3 Gender differences in reported knowledge of regular partner's HIV status ( $n=180)$

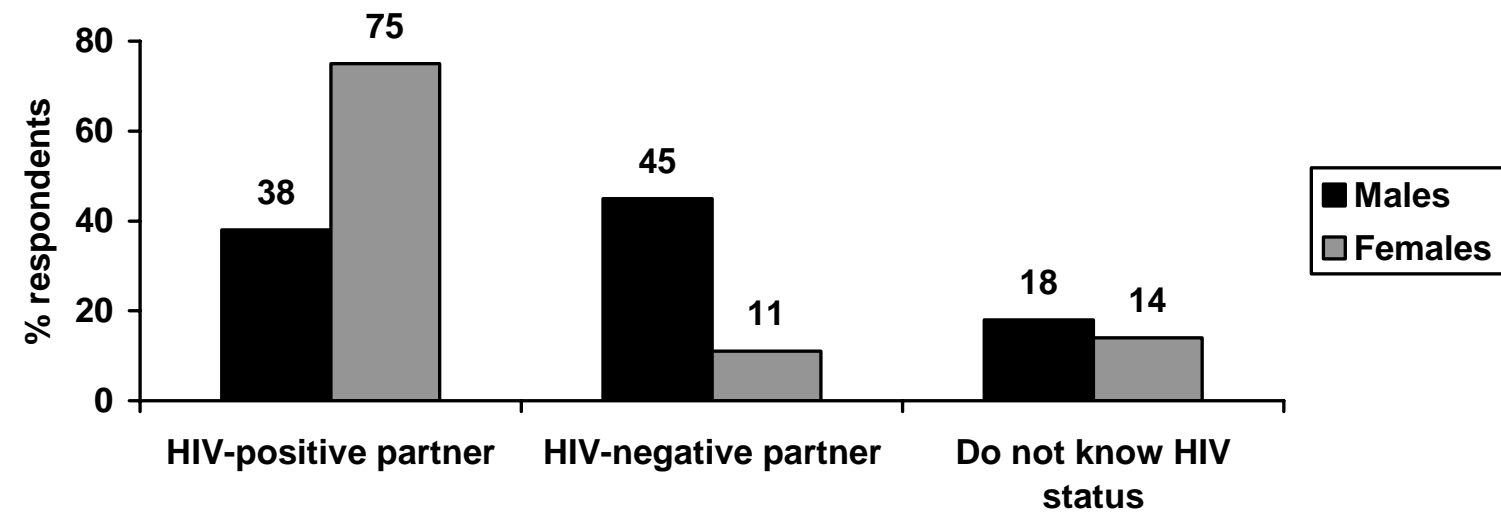

As Table 11 shows, fewer respondents with less than five years of school education were likely to report knowing their regular partner's status than those with more than six years of education or university education. However, the difference was not statistically significant. Time since diagnosis of HIV and time on treatment with antiretroviral therapy were also not associated with knowledge of partner's HIV status.

Table 11 Knowledge of regular partner's HIV status $(n=180)$

\begin{tabular}{lcc}
\hline & \% know & Significance* \\
\hline Education & & .365 \\
Less than 5 years of school $(n=23)$ & 69 & \\
6 to 12 years of school $(n=88)$ & 87 & .374 \\
University $(n=69)$ & & \\
Time since HIV diagnosis & 79 & \\
Less than 12 months $(n=34)$ & 79 & .344 \\
13 to 24 months $(n=47)$ & 86 & \\
More than 24 months $(n=99)$ & & \\
Time since starting ART & 81 & \\
Less than 12 months $(n=77)$ & 82 & \\
13 to 24 months $(n=44)$ & 86 & \\
More than 24 months $(n=59)$ & & \\
\hline
\end{tabular}

Note: Percentages rounded off to nearest whole ${ }^{*}$ Chi Square Test

Disclosure of own HIV status to regular partner: Overall, 74 percent of respondents reported having disclosed their HIV status to their regular partner, and 98 percent of these individuals were married. Among married respondents 25 percent reported not having disclosed their HIV status to their spouse. 
As Table 12 shows, fewer men reported having disclosed their HIV status to their regular partner compared to women (73 percent versus 82 percent), but the difference was not statistically significant.

Education, time since diagnosis of HIV disease (time since testing positive), and time on ART were not found to be significantly associated with disclosure of HIV status to regular partners.

Respondents with advanced HIV disease (defined as CD4 cell counts $<100$ cells $/ \mathrm{mm}^{3}$ at start of ART) reported significantly lower disclosure rates when compared to respondents with less advanced disease stages (CD4 cell counts between 100-200 cells $/ \mathrm{mm}^{3}$ at start of ART and respondents with CD4 cell counts $>200$ cells $/ \mathrm{mm}^{3}$ at start of ART).

Disclosure was significantly associated with a regular partner's HIV status. Respondents with a HIVpositive partner were significantly more likely to report disclosure of their HIV status compared to respondents with an HIV-negative partner or respondents with a partner of unknown HIV status. The lowest disclosure rates were observed with partners of unknown HIV status. 


\section{Hgrizons}

Table 12 Disclosure of own HIV status to regular partners and reported condom use with partner at last sex $(n=179)$

\begin{tabular}{|c|c|c|c|c|}
\hline & \multicolumn{2}{|c|}{ Disclosure } & \multicolumn{2}{|c|}{ Condom use } \\
\hline & $\%$ disclosed & Significance & $\%$ used & Significance \\
\hline \multicolumn{5}{|l|}{ Gender } \\
\hline Male $(n=133)$ & 73 & .301 & 90 & $.206^{\star}$ \\
\hline Female $(n=46)$ & 82 & & 82 & \\
\hline \multicolumn{5}{|l|}{ Education } \\
\hline $\begin{array}{l}\text { Less than } 5 \text { years of school } \\
(n=23)\end{array}$ & 70 & .824 & 65 & .001 \\
\hline 6 to 12 years of school $(n=87)$ & 76 & & 92 & \\
\hline University $(n=69)$ & 74 & & 93 & \\
\hline \multicolumn{5}{|l|}{ Time since HIV diagnosis } \\
\hline Less than 12 months $(n=33)$ & 70 & .072 & 79 & .134 \\
\hline 13 to 24 months $(n=47)$ & 63 & & 89 & \\
\hline More than 24 months $(n=80)$ & 81 & & 92 & \\
\hline \multicolumn{5}{|l|}{ Time since starting ART } \\
\hline Less than 12 months $(n=76)$ & 71 & .317 & 86 & .436 \\
\hline 13 to 24 months $(n=44)$ & 71 & & 93 & \\
\hline More than 24 months $(n=59)$ & 81 & & 90 & \\
\hline \multicolumn{5}{|l|}{ CD4 count at start of ART } \\
\hline Less than 100 cells $/ \mathrm{mm}^{3}(\mathrm{n}=70)$ & 64 & .040 & 89 & .415 \\
\hline 101 to 200 cells $/ \mathrm{mm}^{3}(\mathrm{n}=71)$ & 83 & & 92 & \\
\hline More than 200 cells $/ \mathrm{mm}^{3}(n=35)$ & 74 & & 83 & \\
\hline \multicolumn{5}{|l|}{ Partner HIV status } \\
\hline HIV-positive $(n=78)$ & 83 & .003 & 83 & .051 \\
\hline HIV-negative $(n=70)$ & 74 & & 96 & \\
\hline Don't know $(n=31)$ & 52 & & 87 & \\
\hline \multicolumn{5}{|l|}{ Depression } \\
\hline Minimal to mild $(n=125)$ & 70 & .069 & 94 & .002 \\
\hline Moderate to severe $(n=55)$ & 83 & & 78 & \\
\hline
\end{tabular}

Note: Chi Square Test unless otherwise noted

*Fishers Exact Test

Condom use with a regular partner: Eighty-nine percent of respondents used a condom the last time they had sexual intercourse with their regular partner. Ninety-eight percent of respondents who reported having had sex with a regular partner during the reference period were married. Of these, 89 percent reported using a condom with their spouse the last time they had sex.

As shown in Table 13, a higher proportion of male respondents reported condom use during their last sexual experience with a regular partner compared to female respondents ( 90 percent versus 82 percent), 
but the difference was not statistically significant. Condom use was not found to be associated with time since diagnosis of HIV (testing positive for HIV), disease stage (defined by CD4 cell counts at start of ART), or time on ART.

Respondents with less than five years of education reported significantly lower condom use compared to those with higher levels of education.

Condom use was more common with an HIV-negative partner. Ninety-six percent of respondents with an HIV-negative partner reported using a condom at last intercourse compared to 83 percent with a HIVpositive partner and 87 percent with a partner of unknown HIV status.

Patients with moderate to severe depression reported lower condom use compared to those with minimal to mild depression, and the difference was statistically significant.

Consistent condom use (always used a condom) with a regular partner was reported by 80 percent of respondents (data not shown).

Patients who reported not using a condom at last intercourse with their regular partner $(\mathrm{n}=20)$ were asked why. Having an HIV-positive partner was the most frequently cited reason, followed by dislike of condoms and lack of awareness of the importance of condom use by HIV-positive persons (Table 11).

Table 13 Reasons for not using a condom at last sex with a regular partner $(n=20)$

\begin{tabular}{lc}
\hline Reason & Number of times mentioned \\
\hline Partner is HIV-positive & 6 \\
Don't like using condoms & 3 \\
Did not know about using condoms for this disease & 3 \\
Did not feel the need to use condoms & 2 \\
Found it difficult to discuss condoms & 2 \\
Did not have condoms at hand & 2 \\
Never used condoms & 1 \\
Not disclosed status to partner & 1 \\
Condoms take away romance from sex & 1 \\
Would make partner suspicious & 1 \\
Condoms are difficult to use & 1 \\
\hline
\end{tabular}

Note: Respondents could report more than one reason 


\section{Hgrizons}

\section{Relationships with casual partners, sex workers, and male partners}

Eight (all males) of the 187 respondents who reported being sexually active in the past six months reported sex with a casual partner. Two respondents had been on ART for less than 12 months, two were on ART for 12 to 24 months, and four had been on ART for more than 24 months.

Three males reported having sex with a sex worker. One respondent had been on ART for more than 12 months and two had been on ART for more than 24 months.

Five of eight respondents who reported having sex with a casual partner did not know their partner's HIV status and the other three thought their partner was HIV-negative. Only one respondent reported actually asking his casual partner about her HIV status. The three respondents who reported sex with a sex worker did not know her HIV status. None reported asking about the sex worker's HIV status.

All eight respondents who reported having sex with a casual partner and the three respondents who reported having sex with a sex worker reported not disclosing their own HIV status to these partners. However, all 11 reported using a condom the last time they had sexual intercourse with them.

Whereas two percent (4 out of 260) of male respondents reported ever having sex with a male partner, none reported having sex with a male partner during the reference period. 


\section{Discussion}

The study was designed to be an exploratory study on adherence and included HIV-infected individuals accessing services in both private and public sector health facilities. As the free national ART program had not yet started, patients from public sector sites were recruited from employer-provided, insurancebased health programs. Although a majority of the patients were employed in either the public or private sectors, they were not representative of all HIV-infected individuals accessing ART in India at the time of the study. However, study findings provide important insights into adherence, sexual behavior, and the economic burden of treatment that are relevant to the national ART program as it scales up.

The study results show high levels of adherence in a large proportion of HIV-infected adults receiving ART at one private and three public sector facilities in a developing country and resource-limited setting. This study also found that patients who had insurance coverage resulting in the availability of free ARVs had lower adherence on all measures of adherence, which demonstrates an association between insurance coverage and adherence. These differences in adherence levels were seen even after controlling for economic status. It is important to emphasize that this study is not a comparison between private and public sector health facilities, but rather a comparison between HIV-infected individuals who pay a significant amount of out-of-pocket costs and those who pay a small proportion of their salary into an employer-provided insurance program to receive free ART. Possible explanations for the differences between the two groups include:

- Neither the private nor public sector facilities had formal adherence support programs or adherence counseling services in place, although doctors at all facilities provided adherence-related information to their patients. However, patients in the private sector were assessed for their ability to afford treatment and their readiness to start therapy prior to initiating ART. Thus, this difference in patient preparation prior to initiating ART may have contributed to the differences in adherence measures between the two groups.

- The disease stage at which ART was initiated may have had an influence on adherence levels. The majority of patients who paid out-of-pocket for their treatment initiated ART with very advanced HIV disease and so may have experienced serious and/or life-threatening opportunistic infections. As free ARVs were available, doctors in the public sector may have initiated treatment based on clinical staging and less stringent CD4 cell criteria, as is evident from the proportion of patients in the public sector with higher baseline CD4 counts when compared to patients in the private sector. These patients may not have experienced severe opportunistic infections with higher CD4 cell counts, and as a result, this may have influenced their perceptions about disease severity and the need to maintain high levels of adherence.

- Patients in the private sector were paying significantly higher amounts out-of-pocket for medications and laboratory tests than patients in the insurance programs who paid relatively insignificant amounts when accessing services. These differences may have influenced how each group valued its treatment, thereby contributing to differences in adherence.

- Patients in insurance-based programs usually procured medications from selected public sector dispensaries, which in turn needed to request medications from central suppliers. This requires advance 


\section{Hgrizons}

planning to prevent stock-outs. Purchasing medications from chemists' shops often ensures better availability. Stock-outs and breaks in availability of ARVs in public sector dispensaries and patients' financial difficulties may have contributed to lower adherence among this group. Running out of pills, including stock-outs, was the third most common reason cited by respondents for missing doses over the past week.

Severe depression was found to be an independent predictor of lower adherence in this study. In their review paper, Ichovics and Meade (2002) noted that a similar finding had been reported in other studies. Providers need to be alert to the presence of depression among their patients. Early identification and management of severe depression and interventions to provide adherence support may be required to maintain high levels of adherence.

On univariate analysis, the study found that lower education, starting ART at higher baseline CD4 cell counts, being unemployed, having moderate to severe side effects, and taking four or more medications (in addition to severe depression and receiving free ARV medications) were factors associated with lower adherence. Although these factors were not independent predictors of adherence on multivariate analysis, it is important that providers keep them in mind when deciding if certain patients need stronger adherence counseling and support.

There was widespread concern that patients on ART would become less adherent once they began to feel better physically. This study did not find any evidence supporting this view. There was no significant difference in the mean self-reported 4-day adherence between patients who had been on ART for less than 12 months, 13 to 24 months, or more than 24 months.

The study found that patients accessing ART services in the private sector were almost equally distributed across the four economic status quartiles based on ownership of assets. Patients from employer-supported insurance programs were distributed mostly across the first three economic status quartiles. In India almost 80 percent of health care is provided by the private sector, and people from lower economic strata also access services in the private sector. This study shows that poorer people also access the private sector for ART services, despite the great expense. Additionally, the study found that economic status was not related to adherence, a finding similar to the results of other studies (Ichovics and Meade 2002). However, 71 percent of the patients accessing services at RHC reported that they would move to the national ART program once it started, mostly for financial reasons. It would be interesting to see whether adherence levels change among clients who move from the private sector to public sector health facilities for ART.

Other research findings have identified side effects as an important factor that influences adherence (Ichovics and Meade 2002). This study found that the majority of respondents had low side effect scores, indicating that side effects were present but not particularly bothersome. There were no differences in side effect scores for different durations on ART. Higher side effect scores were reported by women and respondents who started treatment with higher baseline CD4 counts. This suggests that patients who are very sick and for whom ART is a life-saving treatment may tolerate side effects better than others. With regard to women this may be an indication of a difference in the severity of side effects or lower levels of tolerance.

The majority of respondents were married and most of the reported sexual activity in this study was with a regular partner. More than a third of respondents (39 percent) were in a discordant relationship with an 
HIV-negative partner and this was disproportionately higher for male respondents. A quarter of married respondents had not disclosed their HIV status to their partners. Disclosure was lower to a HIV-negative partner and lowest to a partner of unknown HIV status, which highlights the need for prevention counseling programs to emphasize and facilitate disclosure of HIV status to partners.

Overall reported condom use with a regular partner was high. Although 96 percent of respondents with an HIV-negative regular partner reported using a condom at last sexual contact, condom use with a partner of unknown status was lower (87 percent). Lower disclosure to partners of unknown status coupled with lower condom use sets the stage for the risk of transmission of infection to these partners.

The percentage who reported consistent condom use with a regular partner was less than the percentage who reported condom use at last sexual contact; a fifth did not use condoms consistently. Inconsistent condom use coupled with a high proportion of discordant couple relationships and couples with partners of unknown status is a matter of concern. Inconsistent condom use is also a concern for sero-concordant partners because of the risk of re-infection with new viral strains, which in turn accelerate disease progression. Not using condoms also carries the risk of unwanted pregnancy and the subsequent transmission of HIV to the child.

It was encouraging to observe that even though the majority of respondents who reported sex with a casual partner or sex worker did not know their partner's HIV status nor disclose their own status, all reported using a condom at last sexual contact with these partners. We are, however, unable to rule out the extent to which social desirability may have influenced these and other sexual behavior responses. Although the study found some evidence of risk behaviors among respondents on ART (e.g., unprotected sex, sex with casual partners and sex workers), overall there were relatively low levels of reported risky behavior. Low-risk behavior may be explained when taking into account many study participants' history - getting tested and diagnosed, having HIV disease advanced enough to warrant treatment, and having had several contacts with health workers (treating physicians, nurses, counselors, etc.) who conveyed prevention and protection messages during the course of treatment.

Although there is concern that risky sexual behavior may dramatically increase once HIV-positive persons feel better on treatment, this study did not support this view. There were no significant differences in sexual behavior, disclosure rates, and condom use by respondents on ART for different periods of time (less than 12 months, 13 to 24 months, and more than 24 months). 


\section{Hgrizons}

\section{Program I mplications and Recommendations}

This exploratory study was conducted among HIV-infected individuals accessing ART in two categories of health service facilities: the private sector and the insurance-based public sector. In April 2004, the national ART program opened a third sector: free ART at selected public sector facilities.

Although overall adherence among study participants was high, the data indicate that adherence was lower among patients who received free ART through insurance-based programs. No information is available yet on adherence levels among patients who are receiving free ARVs through the national ART program to which the data from this study could be compared. Therefore, there is need for a larger multisite study with HIV-infected persons receiving free ART through the national ART program.

Additionally, almost 80 percent of health care in India is provided in the private sector, which consists of a heterogeneous mix of providers ranging from small individual physician practices, to polyclinics, NGOs, charitable clinics, research institutes, private hospitals, nursing homes, etc. This research highlights the need for more studies with a range of private providers and facilities to better understand the dynamics of adherence in this sector.

Lower adherence among patients receiving free ARVs through insurance-based, public sector facilities highlights the need for a strong monitoring and evaluation component in the national ART program as it scales up. The program may benefit from a strong focus on:

- Adequate education of patients about ART issues (including adherence and side effects) prior to initiation.

- Regular assessments of adherence levels during follow-up.

- Provision of ongoing adherence support where needed, even as evidence on adherence and risk behavior in the program is being gathered.

The small number of patients with insurance coverage who accessed services at NRH and ESIC raises the important question of why so few people chose to access free ARVs at these sites. This makes it imperative to carry out research into the potential barriers to treatment access at these sites, such as lack of awareness of the program among the target population, lack of awareness of the program among health providers, poor health provider training and attitudes, lack of VCT services, and stigma and discrimination issues, among others.

This study included relatively few women. Although the respondents were not representative of the entire population accessing ART services in India, the low figure still calls attention to the need for policymakers to make sure that women are included in the national ART program.

The study indicated that a significant proportion of patients would switch to the free ARV program if their concerns about the quality of ARV medications, confidentiality, and continuous supply of medications were met. This means that the national ART program needs to pay attention to quality of care while preparing for an influx of patients who currently access care services in the private sector.

The study found that out-of-pocket expenses for treatment (ARV medications, treatment monitoring, and consultation fees) pose a significant economic burden on clients who pay for services. The study also found that out-of-pocket expenses influence adherence in a positive way. However, there is probably a 
fine line between out-of-pocket expenses fostering adherence and free ARVs resulting in suboptimal adherence. This has significant implications for the design of a treatment program, and the optimal pricing of it to elicit maximum adherence. It is clear that these study results need to be further investigated; therefore, policymakers should consider further operations research to determine optimal levels of user fees to maximize adherence.

During adherence risk assessment of patients before the initiation of ART, health providers should focus on depression as a key predictor of lower adherence. Health providers may also need to focus on other factors that may influence adherence to a lesser degree: lower education levels, starting ART at higher baseline CD4 cell counts, being unemployed, having moderate to severe side effects, and taking four or more medications.

Traditionally prevention programs in India have focused on high-risk groups such as sex workers, men who have sex with men, truckers, etc. The evidence from this study highlights the need for expanding the scope of prevention programs to include HIV-positive populations, with a special emphasis on facilitating disclosure and consistent condom use within regular partner relationships. Although sero-discordant couples remain the focus of prevention efforts, sero-concordant couples also need to be kept in mind because the risk of reinfection with a different strain of HIV remains. Prevention-related interventions that integrate HIV prevention activities with HIV/AIDS care services are required. 


\section{Hgrizons}

\section{References}

Chen, S. Y. et al. 2002. Continuing increase in sexual risk behaviour and sexually transmitted diseases among men who have sex with men. American Journal of Public Health 92:1387-1388.

Duong, M. et al. 2001. "Evaluation of the patient medication adherence questionnaire as a tool for self reported adherence assessment in HIV-infected patients on antiretroviral regimens," HIV Clinical Trials 2(2):128-135.

Ickovics, J. R. and C. S. Meade. 2002. "Adherence to HAART among patients with HIV: Breakthroughs and barriers," AIDS Care 14(3):309-318.

Katz M. H., et al. 2002. "Impact of highly active antiretroviral therapy on HIV sero-incidence among men who have sex with men: San Francisco," American Journal of Public Health 92:388-394.

Liu, H., et al. 2001. "A comparison study of multiple measures of adherence to HIV protease inhibitors," Annals of Internal Medicine 134:968-977.

Maggio, F. et al. 2005. "Similar adherence rates favor different virologic outcomes for patients treated with non-nucleoside analogues and protease inhibitors," Clinical Infectious Diseases 40:158-63.

Morbidity Mortality Weekly Report. 1999. "Increase in unsafe sex and rectal gonorrhea among men who have sex with men-San Francisco 1994-1997," MMWR 48:45-48.

National AIDS Control Organisation (NACO). 2004. NACO Annual Report 2002-04. Delhi: Ministry of Health and Family Welfare and Government of India. www.nacoonline.org

- 2002. Feasibility study of administering short-term AZT intervention among HIV-infected mothers to prevent mother to child transmission of HIV.

Paterson, D. L., et al. 2000. "Adherence to protease inhibitor therapy and outcomes in patients with HIV infection," Annals of Internal Medicine 133(1):21-30.

Stolte, I. G., et al. 2001. "Increase in sexually transmitted infections among homosexual men in Amsterdam in relation to HAART," Sexually Transmitted Infections 77:184-186.

Van der Ven, P., et al. 2002. "Increasing proportions of Australian gay and homosexually active men engage in unprotected anal intercourse with regular and casual partners," AIDS Care 14(3):335-341.

Weiss, S. D., et al. 2004. "Higher rates of viral suppression with non-nucleoside reverse transcriptase inhibitors compared to single protease inhibitors are not explained by better adherence," HIV Clinical Trials 5(5):278-87.

UNAIDS. 2004. 2004 Report on the Global AIDS Epidemic. Geneva: UNAIDS. 
Beck, A. T. 1996. Beck Depression Inventory ${ }^{\circledR}-I I$ Manual. The Psychological Corporation.

National Institute of Health/National Institute of Allergy and Infectious Diseases. 1999. "Symptom distress module-NIAID Adult AIDS Clinical Trials Group," www.fstrf.org/qol/aactg/adult_ql.html. 


\section{Hgrizons}

Horizons is a global operations research program designed to:

- Identify and test potential strategies to improve HIV/AIDS prevention, care, and support programs and service delivery.

- Disseminate best practices and utilize findings with a view toward scaling up successful interventions.

\section{(2) Population Council}

Horizons is implemented by the Population Council in collaboration with

- International Center for Research on Women (ICRW)

- International HIV/AIDS Alliance

- PATH

- Tulane University

- Family Health International (FHI)

- Johns Hopkins University

For more information, please contact:

Horizons Program, Communications Unit 4301 Connecticut Avenue, NW Suite 280 Washington, DC 20008 USA

Tel: 202-237-9400

Fax: 202-237-8410

Email: horizons@pcdc.org www.popcouncil.org/horizons 